\title{
PrESENCIA Y FUNCIÓN DE LOS ENCAPSULADORES EN LAS CRÓNICAS PERIODÍSTICAS DEL S. XVII
}

\author{
Margarita Borreguero Zuloaga \\ Alvaro S. Octavio de Toledo y Huerta \\ Universidad Complutense de Madrid
}

\begin{abstract}
RESUMEN
Este trabajo parte de la hipótesis de que la aparición de la prensa escrita como medio de comunicación con un objetivo predominantemente informativo, especialmente a partir de su progresiva difusión a sectores más amplios de la sociedad, conllevó el desarrollo y afianzamiento de una serie de mecanismos lingüisticos que acabaron por configurar el particular estilo que hoy conocemos como lenguaje periodístico. Aqui prestaremos especial atención a un tipo de construcciones nominales de carácter anafórico que juegan un importante papel en la cohesión de los textos informativos. El análisis de un corpus de textos pre-periodísticos del s. XVII nos ha permitido trazar un interesante recorrido a través de la creciente complejidad e importancia que dicho mecanismo cohesivo adquiere, muy particularmente en la estructura informativa del texto, en la que actúa a la vez como síntesis de la información ya presentada y como punto de arranque para la introducción de nuevos contenidos.
\end{abstract}

Palabras clave: lenguaje periodístico, encapsuladores, cohesión, s. XVII, estructura informativa.

\section{ABSTRACT}

The development of specific linguistic structures prompted by the settlement of the journal as a widespread mean of communication with a mainly informative aim is the general thesis underlying this paper as part of a wider research program currently developed by the authors. Attention will be paid to the presence of a type of anaphorical nominal constructions which play an important role as cohesive devices in the construction of informative texts. The analysis of pre-journalistic texts from the $17^{\text {th }}$ century offers an interesting thread to study the increasing importance and complexity acquired by this kind of noun phrases, which, furthermore, accomplish an essential function in the text informational structure, acting at the same time as a synthesis of the information already presented and as a point of depart for the new one.

Keywords: journalism, cohesion, 17th century, text informational structure, anaphorical constructions 
Partiendo de la hipótesis de que el desarrollo del género periodístico ha propiciado el afianzamiento de diversos patrones y recursos discursivos como respuesta a las nuevas necesidades de informar a un público cada vez más amplio y más desligado de la situación de producción de la noticia, en este trabajo nos centraremos en la aparición y evolución de un mecanismo de cohesión textual que juega un papel fundamental en la organización informativa del discurso: los encapsuladores. A nuestro juicio los encapsuladores adquieren mayor presencia en este género de textos a medida que se va afianzando lo que, de manera intuitiva y sin ocuparnos ahora de definirlo con mayor precisión, podemos llamar el lenguaje periodístico.

Nuestro estudio se basa en textos pre-periodísticos y periodísticos del s. XVII, desde la década de 1620 a la de 1680 , y nuestro objetivo es comprobar si existe realmente un aumento de la frecuencia de uso de estos mecanismos y una orientación hacia la polifuncionalidad, que parte del papel meramente ilativo con el discurso anterior para ir adquiriendo funciones valorativas y manipuladoras de la información, como las que realizan en la prensa actual.

En primer lugar, introduciremos brevemente el concepto de encapsulador tal como lo entendemos aquí; a continuación, presentamos los textos que conforman nuestro corpus y, por último, expondremos el análisis realizado y los resultados a que nos ha conducido nuestra investigación.

\section{EL CONCEPTO DE ENCAPSULADOR.}

Un encapsulador es un sintagma nominal que cumple los siguientes requisitos:

1. Hace referencia a un fragmento de discurso anterior, es decir, tiene función anafórica.

2. Precisamente para poder realizar esta función anafórica debe tratarse de un sintagma definido, introducido en la mayor parte de los casos por un artículo determinado o un demostrativo.

3. Uno de los integrantes de este sintagma debe ser al menos un sustantivo cuyo contenido léxico mantenga una relación semántica de hiperonimia o de condensación informativa respecto del fragmento discursivo al que hace referencia (de ahí el término de «encapsulador»).

4. El encapsulador prototípico ocupa una posición temática en la oración que introduce $^{1}$, es decir, ocupa la posición inicial. Con frecuencia esta posición se

\footnotetext{
1 Para una exposición detallada de los conceptos de posición temática y posición remática empleados en este trabajo, cfr. Borreguero Zuloaga (2004, 2006a). A partir del planteamiento que se expone en los artículos citados, los autores han dedicado varios estudios a analizar la organización informativa de los textos periodísticos de los ss. XVII a XIX (v. bibliografía). Un estudio más detallado de la función de los encapsuladores en la organización informativa textual en Borreguero Zuloaga (2006b).
} 
reserva para aquella información que se considera más accesible para el receptor. Esto no quiere decir que no haya encapsuladores en posición remática, pero en este trabajo prestaremos especial atención a aquellos encapsuladores que aparecen en posición inicial de oración y que, introduciendo una información supuestamente conocida para el receptor, sirven de punto de arranque para la información novedosa.

A continuación ofrecemos algunos ejemplos de encapsuladores tal y como aparecen en la prensa actual. Su presencia es tan abrumadora que nos ha bastado con un solo número del diario $\mathrm{ABC}$ para encontrar los más variados ejemplos de los distintos aspectos que queremos resaltar:

(1) Durante el mandato de Aznar, el PSOE montaba a los obreros navales en autobuses y los llevaba a manifestarse contra el Gobierno; incluso algún dirigente andaluz les endilgó una arenga subido en un cajón a pie de fábrica. Aquellas movilizaciones quedaban la mar de fotogénicas [...] (Ignacio Camacho, «Sin huelga por vacaciones», $A B C, 22$ de julio de 2006, p. 5).

(2) En su sentencia, el Supremo considera que tales expresiones «indubitativamente manifestaban el carácter político del acontecimiento». Es ese matiz político la base de la sentencia, ya que, como consideró en su día el MADOC y confirmó ayer el Supremo, es falta grave la asistencia «de uniforme o haciendo uso de su condición de militar a cualquier reunión pública o manifestación sindical si tiene carácter político».

Este posicionamiento del Tribunal Supremo se produce después de que el pasado 11 de julio $[\ldots](A B C, 22$ de julio de 2006, p. 13).

(3) El objetivo del Gobierno de las islas es que las autonomías, que integran este órgano presidido por Rumí, acojan a al menos un número sustancial de menores.

Hasta ahora la petición canaria solo ha encontrado buena acogida en la Generalitat catalana ( $A B C, 22$ de julio de 2006, p. 18).

Como puede observarse, se trata de sintagmas nominales definidos que condensan con la selección de un sustantivo (a veces acompañado de modificadores adjetivales, como en (3), adverbiales y/o preposicionales, como en (2)) la información referida con anterioridad, sin que haya necesidad de especificar todas las circunstancias de la acción. Estos términos encapsuladores tienen en su mayor parte naturaleza eventiva y en muchos casos el sustantivo seleccionado no es más que la forma nominal derivada del verbo principal del acontecimiento narrado (Azpiazu 2004), como en

(4) El ex presidente del Gobierno José María Aznar reinvindicó ayer las líneas maestras de su política exterior al defender tanto la controvertida foto de las Azores -junto a George Bush, Tony Blair y José Manuel Durao Barroso dio el pistolezato de salida a la guerra de Irak-como las que le inmortalizaron con los pies encima de la mesa en una cumbre canadiense del G-8 durante la última presidencia española de la Unión Europea, en el año 2002. 
$\mathrm{Y}$ dicha reivindicación se produjo de un modo sorprendente [...] (ABC, 22 de julio de 2006, p. 13).

$\mathrm{Al}$ hacer referencia a una información anterior no es necesario precisar quién hizo la reivindicación ni cuál era el contenido de la misma, ni tampoco cuándo se hizo ni dónde. En ocasiones se especifica el agente, como en el texto (2), pero es mucho más frecuente la ausencia de especificaciones que pueden resultar redundantes para el lector, como en (1) y (4).

Este tipo de mecanismo es extremadamente frecuente en el lenguaje periodístico actual fundamentalmente por dos razones:

a. por contribuir a la economía discursiva condensando en un solo sintagma nominal un fragmento de discurso anterior, cuyas dimensiones pueden oscilar entre una oración y varios párrafos. Estos textos que buscan la máxima eficacia informativa han recibido recientemente el calificativo de textos informativamente densos y el estudio de sus peculiaridades lingüísticas ha sido objeto de interesantes estudios (Jansen 2003) ${ }^{2}$.

b. porque la selección de un término (y sus modificadores) para sintetizar los acontecimientos descritos anteriormente constituye un ejercicio de conceptualización de la realidad presentada que queda reflejado en las etiquetas que categorizan los hechos. Esta etiquetación se presta, además, a la introducción de valoraciones subjetivas de forma indirecta, lo que constituye un sutil procedimiento de manipulación informativa. (Méndez García de Paredes 2003) ${ }^{3}$.

No en vano, el mayor número de encapsuladores aparece en los textos de opinión, columnas y artículos de fondo, que son tradicionalmente los de mayor carga ideológica del periódico y los que tienen la intención declarada de inculcar en el lector un determinado modo de ver y entender la realidad, partiendo para ello de una supuesta aceptación a priori de ciertos postulados e ideas. Veamos algunos ejemplos de la función manipuladora de los encapsuladores en la prensa actual:

2 Méndez García de Paredes (2003: 1018-19) observa, sin embargo, acertadamente que «precisamente por ser una estructura que se subordina, puede emplearse de forma recursiva de manera que la incrustación sucesiva de unas estructuras en otras va haciendo más complejo cada uno de los constituyentes oracionales, con lo que, llegado el caso, nos podemos encontrar con oraciones simples [...], pero extremadamente densas en contenido informativo que, aunque rentables, quizá, desde el punto de vista de la cuantificación informativa (condensación), son poco prácticas y operativas desde el punto de vista comunicativo, por el esfuerzo que hay que hacer para descodificar y comprender el contenido (abstracción)».

3 «La nominalización es, pues, un recurso que permite articular y hacer progresar el pensamiento en el discurso, pues al transformar hechos en conceptos permite crear objetos de discurso, temas para el análisis, de manera que no debe extrañar su rentabilidad en textos de opinión, de comentario y enjuiciamiento de los acontecimientos» (Méndez García de Paredes 2003: 1019) 
(5) La llegada de inmigrantes ilegales no cesa y el problema crece a diario $(A B C, 22$ de julio de 2006, p. 4).

(6) Parece desmesurado tildar a Zapatero de antisemita, como acaba de hacer un influyente empresario judío; más atinado resultaría señalar que, con su tosquedad maniquea, nuestro presidente está propiciando ciertas floraciones sociales de antisemitismo irreflexivo y visceral. Este maniqueísmo esquemático se está convirtiendo en una de las características de su acción de gobierno (Juan Manuel de Prada, "Que sea la última vez», $A B C, 22$ de julio de 2006, p. 5).

(7) [...] en uno de esos ejercicios de desmemoria que nos sirve a diario el afán de retorcer los recuerdos con intención de uso político, el BNG acaba de anunciar que no participará este año en la tradicional ofrenda que hace grande a la capital de Galicia, «por sus reminiscencias fraguistas». [...] La membrillada de Quintana y sus muchachos [...] (M. Martín Ferrand, "Otro delirio nacionalista», $A B C, 22$ de julio de 2006, p. 6).

(8) El etarra García montó ayer el numerito en la Audiencia Nacional durante el juicio por el asesinato de Fernando Múgica. Se lió a patadas con las mamparas y acabó llamando al presidente del tribunal «monigote de circo». [...] La chulería macarra del tal García no es nueva en la Audiencia Nacional (C. Martínez Castro, «Los insultos de ETA», $A B C, 22$ de julio de 2006, p. 12).

La llegada de inmigrantes en (5) es considerada un problema, pero no se dice explícitamente que sea un problema, ni se explica por qué constituye un problema, sino que con el encapsulador en posición temática se deja que el lector infiera de alguna manera que cuando se nos habla del problema se está aludiendo a la llegada de inmigrantes, y en ese ejercicio de inferencia acaba llegando a la conclusión de que dicho acontecimiento representa efectivamente un problema social, aceptando de forma inconsciente la equivalencia impuesta por el periodista. En (7) las declaraciones del partido nacionalista gallego relativas a su no participación en la tradicional ofrenda al apóstol son referidas como «la membrillada de Quintana y sus muchachos» sin que medie ninguna estructura atributiva. La posición temática es el lugar privilegiado para las inferencias y las presuposiciones. El rótulo con que el periodista define unas determinadas declaraciones y que implica una cierta forma de entender lo que ha sucedido ocupa el lugar tradicional de la información ya conocida por el lector, que no necesita de ulteriores especificaciones. Lo mismo puede decirse del «maniqueísmo esquemático» de Rodríguez Zapatero en (6) y de «la chulería macarra» de Txapote (alias de García) en (8).

Con estas breves indicaciones creemos que queda suficientemente claro el importante papel que desempeñan los encapsuladores en la prensa actual, como mecanismos de cohesión y como estrategias de manipulación informativa. En este trabajo nos interesa averiguar, desde una perspectiva diacrónica, en qué momento empezaron a convertirse en un recurso habitual del lenguaje periodístico y si presentaban características distintas de las actuales en los textos pre-periodísticos y 
periodísticos del s. XVII. Consideramos que su presencia constituiría una prueba ineludible del afianzamiento de un estilo de prosa que tiene que atender a la eficacia informativa (la mayor información posible en espacios relativamente reducidos), dejando entrever la conciencia de estos primeros avisadores y redactores de diarios acerca de las enormes posibilidades de influir en la opinión pública a través de sus textos.

\section{Descripción del Corpus}

A continuación ofrecemos una descripción de los textos que conforman nuestro corpus, en la que simplemente tratamos de proporcionar algunas claves históricas e interpretativas para que el lector pueda situar en el contexto político y social las obras aquí estudiadas. Hemos procurado seleccionar textos significativos por su notoriedad y extensión, que fueran representativos de diversos periodos del siglo XVII, de modo que no transcurrieran más de 30 años entre una obra y otra. Los cuatro textos escogidos pertenecen, respectivamente, a los primeros años veinte ( $1^{\circ}$ tercio), a los años cuarenta y cincuenta $\left(2^{\circ}\right.$ tercio) y a los años ochenta ( $3^{\circ}$ tercio). En todos los casos, se trata de textos que han sido editados y estudiados en los últimos años y cuya recuperación forma parte de ese intento reciente de profundizar en el conocimiento de la historia del periodismo español ${ }^{4}$.

1. En primer lugar, las cartas que, junto con las relaciones de sucesos y algunas críticas, constituyen la Obra periodística de Andrés de Almansa y Mendoza 5 . Se trata de 17 cartas o gacetas numeradas y fechadas entre abril de 1621 y noviembre de 1624 que, cuarenta años antes de la aparición de la Gaceta nueva, luego Gaceta de Madrid, constituyen el intento más importante de su tiempo de crear un medio informativo de cierta continuidad. En efecto, Almansa puede considerarse el «más importante periodista conocido de los primeros años del reinado de Felipe IV» (Ettinghausen y Borrego 2001: 12), como atestiguan el número de sus escritos y las cuantiosas reediciones que tuvieron algunos de ellos.

Estas cartas constituyen compendios de noticias breves relativas a los sucesos de la corte, en particular a los nombramientos y mercedes reales, a cuestiones políticas y económicas de variada índole, así como a actos de representación y acontecimientos

\footnotetext{
4 «Las investigaciones de los últimos veinte años están contribuyendo a que esa masa de escritos, que tantos y tan inestimables testimonios dan, entre otras cosas, de los mecanismos ideológicos vigentes, de las formas en que se autorrepresenta el establishment y de la visión del mundo que procuraba inculcar éste, ocupe el lugar que le corresponde en el corpus documental de los siglos pasados» (Ettinghausen y Borrego 2001: 11).

5 A. de Almansa y Mendoza, Obra periodística, ed. de Henry Ettinghausen y Manuel Borrego, Madrid, Castalia, 2001. El número de página entre paréntesis que sigue a cada cita corresponde a esta edición.
} 
sociales, pero también relatan algunos hechos políticos ocurridos en el extranjero ${ }^{6}$. Las cartas no aparecieron regularmente a lo largo de estos cuatro años, sino que fueron más frecuentes en determinados periodos (por ejemplo, las siete primeras cartas aparecen entre abril y noviembre de 1621) y mucho más escasas en otros (de noviembre de 1621 a marzo de 1623 solo se publican dos cartas). Si las primeras tienen una forma epistolar clásica - dirigidas a un destinatario individual, aunque anónimo en muchos casos, al que se alude explícitamente-, lo que las emparenta con las cartas de avisos, a partir de la carta 13 se advierte una adaptación al «modelo de las relaciones en el sentido de que [...] sus receptores se definen cada vez con más nitidez» (Ettinghausen y Borrego 2001: 43).

Las cartas tuvieron enorme éxito, a lo que sin duda contribuyó su aparición en un momento histórico propicio, el comienzo del reinado de Felipe IV, en el que había gran avidez de noticias acerca de los primeros movimientos del nuevo gobierno ${ }^{7}$. Pero sería injusto no reconocer que gran parte de ese éxito se debió también a la buena información con que contaba el autor, no pudiendo descartarse que su actividad estuviera impulsada por los propios miembros del gobierno, interesados en ofrecer de sí mismos una imagen muy positiva ${ }^{8}$.

Aunque no tenemos certeza de que todas las cartas de la serie fueran escritas por el propio Almansa y aunque existen ciertas incoherencias formales que hacen sospechar la intervención de más de un autor, en especial por lo que respecta a la variedad de destinatarios (desde el anónimo «un su amigo» hasta el duque de Medinasidonia, pasando por un obispo anónimo y el duque de Béjar), los estudiosos prefieren mantener la atribución de la autoría a Almansa basándose en las referencias que se encuentran en la carta 15 y sobre todo en la 17, donde el autor hace alusión a las cartas escritas anteriormente. El hecho de que todas las cartas aparezcan numeradas correlativamente (con excepción de la última) y de que se encuentren alusiones de unas en otras, atestiguando así una continuidad verdadera o facticia, ha constituido un argumento definitivo, en opinión de sus editores, para considerarlas obra de la misma mano.

El contenido de las cartas privilegia información de tipo político-administrativo acerca del comienzo del reinado de Felipe IV (de hecho, la primera carta es una

${ }^{6}$ Véase la clasificación de las noticias que sigue a la edición citada (Ettinghausen y Borrego 2001: 559-613).

7 Ettinghausen y Borrego (2001: 12) señalan el «acierto de iniciar una producción seriada de cartas informativas tras la muerte de Felipe III, en el momento en que la monarquía hispánica parecía animada por nuevos y ambiciosos proyectos de cambio».

${ }^{8}$ Por otra parte, sin el favor de algún alto cargo sería imposible explicar el acceso de Almansa a información tan puntual y detallada sobre todo lo que ocurría en la corte, teniendo en cuenta además que contaba con no pocas enemistades en el mundo de las letras, como atestiguan los retratos denigratorios que de él hicieron Suárez de Figueroa, Lope de Vega y Quevedo, entre otros. Cfr. Ettinghausen y Borrego (2001: 16-30). 
relación pormenorizada de la muerte de Felipe III) y de los intentos de renovación política, económica y social del nuevo gobierno encabezado por el conde-duque de Olivares. Aunque no se puede hablar de una auténtica actividad propagandística ${ }^{9}$, lo cierto es que los textos contienen numerosos elogios, a veces excesivos, del joven rey y su gobierno. Esta actitud se hace extrema en las 17 relaciones de sucesos firmadas por el autor (que no serán objeto de nuestro estudio), con las que guardan estrecha relación la carta primera citada, así como la sexta y la séptima que se dedican a la exposición detallada de un único suceso en cada caso.

Por último, merece la pena destacar el interés de Almansa por no quedar en la sombra como un avisador anónimo más, aunque dicho interés se aprecia mejor en sus relaciones (todas firmadas) que en sus cartas; y la defensa que hace del oficio de informador frente a sus detractores, manifestando una temprana y loable conciencia de la importancia de informar, más allá de los comunicados oficiales, especialmente a aquellos ausentes de la corte ${ }^{10}$.

2. Los Avisos de José Pellicer de Tovar, fechados entre el 17 de marzo de 1639 y el 29 de noviembre de 1644, son una colección de noticias destinadas a un anónimo ${ }^{11}$ en las que ha desaparecido ya cualquier resto de forma epistolar. Cada aviso era un pliego que formaba un cuaderno de cuatro hojas en las que, por lo general, la división en párrafos se corresponde con una cuidadosa separación de las distintas noticias. Estos avisos aparecían semanalmente y solo existe una importante interrupción entre el 16 de septiembre de 1642 y el 1 de julio de 1643, para la que los estudiosos no han encontrado todavía una explicación. Nos encontramos, por tanto, ante una continuidad informativa desconocida hasta el momento.

El propio autor nos dice servirse de fuentes extranjeras, fundamentalmente cartas de mercaderes o viajeros o incluso de algún conocido, pero no se puede descartar que llegara a sus manos alguna gaceta de las que se publicaban en Amberes o en Venecia. «Días ha que no tenemos correo de Italia, de Alemania y Flandes, con que no se

${ }^{9}$ Si bien los editores hablan de una «visión gubernamentalista» (Ettinghausen y Borrego 2001: 62).

10 Pero también a los propios madrileños, pues el mismo autor nos relata que sus cartas, aparentemente escritas para un único destinatario, eran impresas y vendidas en Madrid. Aunque Ettinghausen y Borrego no lo digan abiertamente en su introducción a la edición, poca duda nos queda de que dicha impresión se realizaba instigada por el propio Almansa, que en varios pasajes pone de manifiesto su conciencia de que escribía para un público más amplio. Sus reproches al destinatario anónimo por no tener el suficiente cuidado en impedir la difusión de sus cartas son seguramente una triquiñuela retórica para esconder su ambición por dar a conocer las noticias recabadas entre los personajes de la corte más allegados a las instancias del poder.

11 Se sabe, sin embargo, que entre los destinatarios de su correspondencia se encontraban Quevedo, Miguel Batista de Lanuza, caballero del Consejo de Aragón, y otros miembros de la nobleza. 
podrán avisar novedades de guerra» (p. 24). La posibilidad de que muchos de sus avisos fuesen adaptaciones de textos italianos o franceses explicaría en parte la riqueza de determinados recursos expresivos en Pellicer, que, unida a su completa formación historiográfica y humanística, darían cuenta del amplio aliento de su prosa.

En efecto, la mayor extensión de las noticias y el empleo de una prosa mucho más cuidada, en la que han desaparecido tanto la monotonía sintáctica, que aún encontraremos en Barrionuevo, como los barrocos excesos ornamentales de Almansa, nos advierten de la presencia del que quizá sea nuestro primer periodista moderno. Es notable la preocupación por la minuciosidad informativa y por evitar las ambigüedades, señal de que era consciente de dirigirse a un amplio público que contaba seguramente con distintos grados de información relativa a los hechos.

A diferencia de Almansa, pero como más tarde hará Barrionuevo, Pellicer prefirió no publicar sus Avisos, lo que le permitía una libertad de expresión mucho mayor para ofrecer abiertamente sus opiniones acerca de los sucesos relatados ${ }^{12}$, aunque hay que señalar su mayor comedimiento frente a los irónicos comentarios de Barrionuevo. Sus noticias son mayoritariamente políticas y, debido a sus fuentes y al convulso momento histórico, especialmente atentas a las guerras, campañas y acontecimientos que tenían lugar en España y en el resto de Europa. Eso no impide que encontremos algunos relatos de sucesos menores en la corte y otros lugares de la Península, especialmente los de muertes violentas, pero son mucho menos frecuentes las informaciones relativas a los actos sociales y espectáculos de Madrid, con o sin participación regia.

3. Los Avisos de Jerónimo de Barrionuevo recogen los sucesos ocurridos en la corte, junto con las noticias que a ésta llegaban, en los años finales del reinado de Felipe IV. Se trata de 225 cartas enviadas por Barrionuevo a un deán de Zaragoza, cuya identidad se desconoce, pero dirigidas en realidad a un grupo más amplio de personas próximas a este deán, fechadas entre el 1 de agosto de 1654 y el 24 de julio de 1658. En estas cartas se recogen informaciones de tenor más variado que las de Almansa, pues además de las relativas a los acontecimientos políticos, a las campañas militares y los hechos más destacados ocurridos fuera de España, este autor dedica amplio espacio a noticias referidas al día a día en la corte. Es decir, no solo nos relata los festejos y actos en los que participa el rey, desde las comedias a los toros, sino también las fiestas privadas que organizan personajes de la aristocracia y el gobierno, así como sus aventuras y desventuras, además de escándalos, detenciones, robos, violaciones, atracos y toda suerte de sucesos acaecidos en la villa. Esta prolijidad de

\footnotetext{
12 «Cal reconèixer uns contrasts fonamentals entre la premsa impresa i els serveis informatius particulars, com ara els de Pellicer i Barrionuevo. Mentre, per un costat, la premsa impresa tenia, per definició, un impacte en un nombre de lectors, categòricament més elevat, per l'altre, tenia la particularitat immensament significativa de difondre únicament bones notícies. De fet, la comparació entre informació impresa i manuscrita és colpidora, la qual cosa posa de relleu l'impacte de potents controls ideològics sobre els creadors dels mitjans d'informació» (Ettinghausen 2005: 51).
} 
noticias y la frecuencia de sus cartas, semanal por lo general, aunque a veces quincenal, le han valido los calificativos de «mejor representante del periodismo del siglo XVII»o «periodista más genuino del siglo XVII» (Paz y Melia 1968: 4, 12).

Así pues, Jerónimo de Barrionuevo, del que sabemos que fue tesorero de la iglesia de Sigüenza, pero residente en Madrid en los años en que escribió sus Avisos, nos ofrece una visión de Felipe IV muy distinta de la de Almansa. Han desaparecido por completo el optimismo y las esperanzas de renovación que caracterizaron los primeros años de su reinado, para dar paso al desencanto y a una crítica, no exenta de sarcasmo, de los despilfarros de la monarquía y la nobleza, a pesar de la penosa situación económica de la Hacienda real, de los fracasos militares en el extranjero y de los desórdenes sociales de Madrid, que dan pie, como ya anticipábamos, al relato de numerosos sucesos, casi ausentes en las cartas de Almansa. No encontramos tampoco el interés servil de Almansa por congraciarse con los poderosos; antes al contrario, sus textos están repletos de comentarios desdeñosos y burlescos que no respetan ni siquiera al propio Felipe IV. Sin embargo, «esos arranques de noble indignación contra los poderosos que abusaban de su influencia, contra los ricos que malgastaban su fortuna y contra los Mayorazgos que injustamente tenían avasallados y despojaban de su parte de herencia a los segundones» (Paz y Melia 1968: 10) escondían, al decir de sus biógrafos, su propia amargura por la suerte que había tenido que correr como hermano menor del Marqués de Cusano.

Como dijimos más arriba, los Avisos de Barrionuevo no fueron impresos en su época y eso explica las licencias que se tomó Barrionuevo en sus comentarios, mucho más expuestos y atrevidos que los de Almansa, pero a la vez mucho más interesantes para conocer el verdadero sentir de la sociedad ante los desmanes del gobierno. La ausencia del carácter «gubernamentalista» que caracterizaba las cartas de Almansa queda reflejado en la escasez de noticias relativas a los nombramientos oficiales y a las mercedes concedidas por el rey, que constituían casi la mitad de la información suministrada por éste.

4. Las Noticias Extraordinarias del Norte de Pedro de Huarte es la primera gaceta vasca de la que se tiene noticia. Se publicaba bisemanalmente, alternando su publicación con la de las Noticias Principales y Verdaderas (una semana esta gaceta y otra semana la otra). Abandonado ya cualquier vestigio de forma epistolar, con esta obra entramos de lleno en el terreno de los textos periodísticos propiamente dichos. Las gacetas se caracterizaban por recopilar noticias de diversa procedencia relativas a los distintos Estados europeos «ofreciéndolas en sucesivas entregas y siguiendo siempre un mismo esquema de presentación» (Reula, apud. Díaz y Hoyo 2003: 66). Su público era mucho más amplio y estaba formado mayoritariamente por la burguesía comercial donostiarra, que necesitaba conocer qué sucedía en Europa para prever la marcha de sus negocios. Se recibían por suscripción, lo que nos sitúa ya en una concepción moderna del periodismo, donde la información tiene un precio y no es simplemente 
un entretenimiento de aficionados para ocupar el ocio y saciar la curiosidad de los ausentes de la corte a cambio de algunos regalillos, como era el caso de Barrionuevo ${ }^{13}$.

Aunque sabemos que se publicaron semanalmente en San Sebastián desde 1687 hasta 1704, solo se conservan 28 números de 1688 y 1689 de los cuales el primero apareció el 10 de febrero de 1688 y el último el 13 de diciembre de 1689 (se calcula, por tanto, que faltan 17 números). Cada número de la gaceta recogía los sucesos acaecidos en las semanas anteriores y solían pasar más de nueve días de media entre la fecha de la última noticia y la publicación de la gaceta.

No sabemos si, al igual que las Noticias Principales y Verdaderas, las Noticias Extraordinarias del Norte eran traducción de otra gaceta original francesa o reproducción de alguna de las que se publicaban en Flandes en lengua española ${ }^{14}$. Sin embargo, las infructuosas búsquedas de una gaceta original y la ausencia de galicismos en su redacción parecen apuntar más bien a la creación de una oficina de información en el taller de impresión de los hermanos Huarte. No es casual la publicación de dos gacetas contemporáneamente en un lugar como San Sebastián, paso obligado para todos aquellos que marchaban o regresaban del extranjero por la vía de Francia y que llevaban y traían consigo nuevas de toda Europa. Por allí pasaba además el correo de Flandes, con lo cual la ciudad vasca pronto se convirtió en un foco informativo para el resto de la Península.

Las noticias recogidas eran fundamentalmente de naturaleza política y bélica, sobre sucesos ocurridos en el extranjero en su mayor parte, debido a las fuentes de información de que se valían los Huarte, a saber, las cartas de los ejércitos imperiales austriacos. Están fechadas generalmente en Viena y ocasionalmente en otros lugares de Centroeuropa. También se incluyen relaciones más pormenorizadas de capitulaciones, proposiciones, etc. en las que se reproducen íntegramente textos oficiales. Más interesantes son las informaciones que se conseguían comprando los avisos de otros informadores o las que redactaban directamente sobre los acontecimientos locales, si bien estas últimas son más numerosas en las Noticias Principales y Verdaderas.

\section{Presencia de enCapsuladores en los teXtos Del S. XVII}

El primer texto, cronológicamente hablando, de nuestro corpus se caracteriza por la escasa presencia de encapsuladores. La función cohesiva que estos realizan está desempeñada casi exclusivamente por deícticos metatextuales, es decir, por el

\footnotetext{
13 Para muchos talleres de impresión la publicación de gacetas fue una fuente de recursos imprescindible, pues aseguraba unos ingresos seguros, aunque modestos, que les permitían hacer frente a los vaivenes del mercado de libros, «objetos de lujo cuyas ventas se reducían drásticamente en época de crisis» (Díaz y Hoyo 2003: 64-65).

14 Un estudio detallado de esta gaceta y una descripción completa puede encontrarla el lector en el estudio preliminar a su edición facsímil (Díaz y Hoyo 2003: 13-118).
} 
pronombre demostrativo esto, que se refiere anafóricamente a los hechos descritos pero sin introducir ninguna etiqueta o término con función encapsuladora ${ }^{15}$. Esta situación la volvemos a encontrar, con algunas modificaciones que detallaremos a continuación, en el tercero de los textos, los Avisos de Barrionuevo.

Para hacernos una idea del número de encapsuladores y de deícticos metatextuales en un texto actual en relación con el que aparece en los textos de la primera mitad del s. XVII, hemos comparado un extracto de aproximadamente 24.000 palabras del diario ABC de 22 de julio de 2006 (teniendo en cuenta únicamente las noticias de política y sociedad (31 noticias de diversa extensión) y los textos de opinión referidos a dichas noticias (14), pp. 3-34) con uno semejante de los Avisos de Barrionuevo (10 cartas desde el 4 de octubre de 1656 hasta diciembre de 1656, vol. II, pp. 1-32).

\begin{tabular}{|c|c|c|}
\cline { 2 - 3 } \multicolumn{1}{c|}{} & $\begin{array}{c}\text { Encapsuladores en } \\
\text { posición temática }\end{array}$ & $\begin{array}{c}\text { Deícticos metatextuales en } \\
\text { posición temática }\end{array}$ \\
\hline ABC & 39 & 2 \\
\hline Avisos de Barrionuevo & 2 & 19 \\
\hline
\end{tabular}

Sin embargo, los textos de Pellicer contienen un número muy superior de encapsuladores que su predecesor y sucesor inmediatos en nuestro corpus. De modo que comenzaremos analizando las noticias de Almansa y Barrionuevo, para pasar después a la obra de Pellicer y a la gaceta de Huarte, donde ya encontramos modificaciones significativas.

\subsection{Las cartas de Almansa y Mendoza}

Como hemos adelantado, lo más frecuente en este texto es la presencia de los deícticos metatextuales y del pronombre 'ello':

\footnotetext{
${ }^{15}$ En estos primeros textos sería interesante estudiar la gramaticalización de ciertos elementos anafóricos, no solo los demostrativos sino también algunos relativos, que precedidos de preposición llegan a funcionar como auténticos conectores. Por ejemplo: «Ya en Francia han admitido el papel sellado y otras imposiciones de las que por acá tenemos, de que dicen sacará el Rey infinitos ducados» (Barrionuevo, vol. I, p. 158); pero es tema que tenemos que dejar para futuras investigaciones. Por otro lado, conviene recordar aquí la existencia de una construcción típica del español medieval y clásico aunque documentada incluso hasta hoy, el cual + nombre, que tiene función anafórica y aparece frecuentemente en posición temática (... en la ciudad de $X$, la cual ciudad está en $Y$; véase Barra 2007), desempeñando ocasionalmente oficio de encapsulador, como señala Pons (en prensa). La construcción figura desde luego en nuestros textos, pero no con valor de encapsulador en los fragmentos que hemos analizado, hecho que podría ser meramente fortuito, pero también revelador - en la línea de lo que sugieren ambos autores - de una diferencia en la selección lingüística en razón del tipo de texto o la tradición discursiva.
} 
(9) A la princesa Pomblím, viuda, dio el emperador la investidura de aquel estado, y autoridad al rey católico para que la pasase a los sucesores de su casa, y con esto ella casó con el duque de Brazazu, cabeza de la casa de Ursino, y el novio y su hermano el cardenal la llevaron a Roma (p. 195).

(10) Murió el duque de Osuna de sus enfermedades [...]. Murió Garci Pérez de Araciel a 29 de septiembre [...] Llegó la beatificación del santo Francisco de Borja, de la Compañía de Jesús [...] El preñado de la reina nuestra señora se deshizo [...] Legó la nao de la India de Portugal [...] Murió también en este dicho mes el padre fray Simón de Rojas [...] El condestable de Castilla se casó con doña Isabel de Guzmán, hermana del marqués de Toral, menina de la reina. Todo esto se ha platicado en la corte (p. 308).

(11) Diose al licenciado Morquecho, oidor de Lima, la antigüedad que tenía en la audiencia de México, y para ello se mandó librar sobrecédula [...] (p. 237)

En la Carta primera, en que se relata la muerte de Felipe III, encontramos el siguiente pasaje:

(12) Luego por la mañana, martes, fue un coche por [Jerónimo de] Florencia, que le llamaba el rey muy aprisa, enviando el del Infantado tres recados, unos tras otros. En entrando, le salió a recibir a la antecámara el confesor del rey y a apercibir de que tratase a su majestad sólo de cosas de confianza, porque estaba algo descaecido, y dejase lo demás. Respondió Florencia. «Señor, yo soy muy poco entremetido, y de esto vuestra ilustrísima es buen testigo, pues ha visto que en dos años no he entrado por sus puertas y ahora vengo a ver la primera vez a su majestad, que Dios guarde, llamado con tres archeros». "iJesús, padre! ¡Entre vuestra paternidad, que puede entrar aquí como y cuando quisiera!» «Sólo decía esto porque conozco a su majestad y sé lo que ahora es menesten». Con esto entraron en el retrete [...] (p. 168)

El deíctico metatextual hace referencia al diálogo que ha tenido lugar entre los dos clérigos. Un encapsulador referente a ese intercambio, como los que encontramos en la prensa actual, podría haber sido 'con estas palabras', 'tras estos reproches', 'tras esta aclaración', etc. Así aparece algo más adelante en este mismo texto:

(13) Delante de los dos confesores del rey y príncipe (que sin duda les pareció buena devoción para aquel paso) repitió muchas veces su majestad: «iAh, si Dios me diera vida, cuán diferentemente gobernara!». Y estas palabras han traído a la memoria lo que ha andado aquí entre las manos estos años [...] (p. 170)

Son frecuentes también en posición temática hiperónimos muy generales que han perdido su significado léxico y funcionan como deícticos más que como encapsuladores propiamente dichos (Pelo 1986). A continuación ofrecemos dos ejemplos, el primero en función atributiva y el segundo en función de encapsulador. 
(14) [...] don Felipe II, el cual le escogió, aunque más mozo (tal concepto tenía de él), y quiso mostrarle al mundo llamándole a San Lorenzo, haciendo le hospedasen en su casa y sirviesen sus tapicerías y oficios: cosa hasta hoy con nadie reiterada (p. 224).

(15) Famosa fue la victoria de don Juan de Cárdenas, que gobierna a Orán, [...]. También fue mucho la armada del estrecho de Gibraltar, con dieciséis navíos y cuatro pataches, defender el paso a ochenta navíos holandenses y hacerlos retirar con gran pérdida. De estas cosas andan relaciones impresas, y así no se especifican.

Más raros son los encapsuladores que podríamos llamar 'de objeto', como el de este ejemplo en que «vestido» hace referencia al conjunto de los paramentos de las guardas:

(16) Llevaban ropones de tela blanca rica, alcarchofada de oro en el telar, forros de raso de oro y carmesí, jubones de las ropas, calzas y cueras de pasamanos de oro de realce y gorras aderezadas. Cada vestido costo ochocientos ducados (p. 187).

Aunque muy escasos, podemos encontrar algunos encapsuladores de naturaleza descriptiva o eventiva ${ }^{16}$ :

(17) En saliendo a la calle miró a todas partes, considerando la muchedumbre de gente que le esperaba; y, poniendo los ojos en el cielo, estuvo así espacio de dos credos, e inclinándose después al cristo y adorándole devotamente, nunca

16 Mucho más frecuentes son los encapsuladores en posición remática, como el siguiente, donde el hiperónimo «faltas» resume todas las acciones mencionadas con anterioridad: «Hizóle pedir perdón a todos los que hubiese dado algún pesar. Pidiósele a Dios de las omisiones que había tenido en el reinar y de no haber gobernado por su persona, de haber entregado su voluntad a otro que a Dios del cielo, no haber sido cuidadoso en sus obligaciones, no haber sido muy agradecido a sus criados, de no haberles hablado con mucho agrado. Y después de haberse arrepentido en público con grandísima humildad de todas estas faltas [...]» (p. 169).

Otro ejemplo en «Por la otra sentencia, que dicen tiene doscientos y cuarenta y cuatro cargos, le condenan a un millón y doscientos y cincuenta mil ducados [...] fue condenado en perdimiento de todos los títulos y mercedes que su majestad tenía y se le había hecho merced [...] y en perdimiento de los títulos de conde y marqués y capitán de la guarda [...] y en perdimiento del oficio de correo mayor [...] y en perdimiento del patronazgo del monasterio de Portaceli que hizo en la ciudad de Valladolid, [...] y en el oficio que tenía de regidor y escribano de ayuntamiento y depositario de la ciudad de Plasencia y de la ciudad de Soria y villa de Nava y otras. Dícese que llevó este golpe con valor notable [...]» (pp. 196-197).

Sin embargo, no es nuestra intención ocuparnos aquí de este tipo de encapsulación, que contribuye de manera menos evidente a la densidad informativa. Nos limitamos a observar que la abundancia de encapsuladores en el bloque remático parece indicar una escasa conciencia del potencial informativo de estos sintagmas, potencial máximamente explotado, en cambio, en la prensa actual, que los asigna con clara preferencia a la posición inicial temática. 
jamás hasta el cadalso le apartó los ojos. Su confesor llegó a animarle y él respondió: «Padre mío, vamos en buen hora, que a mí no me falta ánimo, porque le llevo muy grande a padecer esta muerte, porque por mí la padeció más deshonrada y abatida mi señor Jesucristo. ¡Ea, vamos en nombre de Dios, pues su majestad lo quiere, que yo voy muy contento a cumplir su voluntad y a pagar mis pecados!». Este valor tuvo siempre (p. 219).

(18) El día de Santa Catalina, yendo los estudiantes, en Salamanca, en el acompañamiento que aquel día se hace al rector, se atravesó un alguacil de la ciudad con un estudiante y se encendió tanto el fuego que se pusieron en armas la ciudad y universidad y llegaron a las manos por dos veces, y fuera grandísimo el daño si la gran prudencia del obispo, maestrescuela, rector y caballeros no lo apaciguara. A la averiguación de este negocio ha ido el alcalde don Luis de Paredes, donde está al presente (p. 230).

En ocasiones el encapsulador se refiere al texto de una carta anterior. Por ejemplo, en la Carta segunda, uno de los párrafos comienza diciendo: «A la muerte de su majestad, siguió la del conde de Salazar [...]» (p. 177) donde «a la muerte de su majestad» es un encapsulador de todo lo narrado en la primera carta. Otros encapsuladores intertextuales, de contenido mucho más vago, son «las cosas de Alemania» (p. 248), «las cosas de Italia» (p. 257), «las cosas de Turquía» (p. 258), que aluden asimismo a hechos narrados en cartas precedentes. La función intertextual del encapsulador es la predominante en el texto de Almansa, pero se ha reducido considerablemente en el lenguaje periodístico actual, lo que posiblemente obedece a la falta de continuidad del destinatario. En efecto, ningún periodista puede partir en el momento de redactar su noticia del supuesto de que su lector de hoy leyó también la noticia que escribió ayer sobre el mismo o diverso asunto, y mucho menos la que escribió la semana pasada, aun cuando el lector sea un lector habitual, por tanto las referencias intertextuales de este tipo son mínimas.

Otro tipo de empleo de encapsulador, que casi ha desaparecido de la prensa actual, es aquél en que el acontecimiento se etiqueta, a veces con un mínimo grado de valoración, pero de forma indirecta, pues el sustantivo encapsulador aparece en un sintagma nominal introducido por 'otros / otras'. Por ejemplo,

(19) Mandó prender al duque de Osuna [...]. Quitáronse los papeles a Tomás Angulo [...] Envió su majestad un recado con el de Santiesteban a Saldaña [...] Dióse el oficio de caballerizo del rey [...] Predicó Florencia el segundo día de Pascua [...] Juró el patriarca sus oficios de capellán [...] A Roque de Campofrío declararon por presidente de Hacienda.

Otras mil preñeces hay que saldrán a la luz a su tiempo, y yo avisaré de ellas. (pp. 175-176)

En este texto el término «preñeces» encapsula todos los acontecimientos de la corte relatados con anterioridad, pero al estar precedido por el indefinido «otros» se da cabida a un conjunto más amplio de acontecimientos, al que pertenecen los relatados. 
En cualquier caso lo interesante de este encapsulador es el uso del término «preñeces» como etiquetador de un serie de hechos, mediante el cual se nos hace presente el 'yo' del informador (Almansa) que promete a sus lectores no solo nuevas noticias, sino noticias sustanciosas («preñeces»). Sin valoración alguna, encontramos otro caso en «Hoy, domingo, partió su majestad a Aranjuez. Muchas provisiones de personas beneméritas y otras mil novedades se prometen cuando vuelva» (p. 188), donde el sustantivo «novedades» encapsula todas las noticias de la carta.

En conclusión, podemos decir que en este primer texto de nuestro corpus la gran mayoría de los escasos encapsuladores que hemos encontrado son aquellos que sirven para aludir a noticias que aparecen en cartas anteriores, siendo en general su presencia muy minoritaria en el interior de una noticia. En la mayoría de los casos son los deícticos metatextuales y los hiperónimos desemantizados los que asumen la función que los encapsuladores tienen en el lenguaje periodístico actual. La ausencia de encapsuladores relativos a los acontecimientos (es decir, los propiamente etiquetadores) así como la falta de adjetivación impiden que estos puedan funcionar como lugares de valoración subjetiva de las noticias. Evidentemente, esto no supone la ausencia de dicha valoración, que podríamos considerar intrínseca a la noticia ya desde la aparición de estos textos pre-periodísticos ${ }^{17}$.

${ }^{17}$ No hay que olvidar, como adelantábamos más arriba, el tono elogioso y casi adulador hacia Felipe IV, el conde-duque de Olivares y otros personajes del gobierno. En efecto, Almansa trata de ofrecer una imagen muy positiva de las primeras iniciativas gubernamentales en el comienzo del reinado de Felipe IV, con el probable propósito de obtener el favor de los poderosos. Estas apreciaciones aparecen con frecuencia en oraciones y párrafos enteros que preceden la presentación de las noticias, como el que se encuentra al inicio de la carta 2: «El mundo se ha revuelto con el nuevo gobierno de esta monarquía, y su majestad (¡Dios le guarde!) la gobierna con tal celo y prudencia que muestran sus acciones la asistencia que le hace el divino espíritu. ¡Consérvele Dios muchos años para que tengan grande aumento tan felices principios!» (vol. I, p. 177)

Así, por ejemplo, es fácil encontrar comentarios que recogen la opinión personal del autor en estructuras predicativas de tipo apositivo: «A don Agustín Mejía dieron la llave, merced bien merecida, y también la dieron al conde de Monterrey». Sin embargo, en el texto de Almansa las estructuras valorativas más frecuentes son las atributivas sin cópula, separadas del texto anterior por un signo de puntuación fuerte. Veamos algunos ejemplos:

«A las nueve y media expiró, ya gozando de mucha paz y quietud, y habiendo dicho antes una oración muy devota que él sabía, y a Nuestra Señora el Hora mortis suscipe, y después de haber pedido el hábito y profesión de la tercera orden de penitencia de San Francisco, que se le dio el padre fray Benigno de Génova, ministro general: muerte digna de ser envidiada de los más santos y espirituales religiosos y anacoretas, y que para de un cartujo era santísima» (vol. I, p. 173).

«Los coches dicen se reforman: acuerdo considerado» (vol. I, p. 181).

I.S.S.N. $1132-0265$

Philologia Hispalensis 21 (2007) 119-153 


\subsection{Los Avisos de Barrionuevo}

Al igual que ocurría con las cartas de Almansa, la presencia de encapsuladores es todavía muy minoritaria en este texto, pero puede advertirse ya un mayor desarrollo de estos. En concreto, empieza a afianzarse el encapsulador que hace referencia a un acontecimiento descrito con cierto pormenor anteriormente. En el texto que citamos a continuación el encapsulador aparece subrayado y el acontecimiento descrito en cursiva:

(20) Dicese haber muerto en Nápoles 200.000 hombres [...] El desorden en los mantenimientos era grande, porque el hambre y la peste igualaban en materia a todos. [...] Y los que morian eran tantos, que sacaban a los condenados a galeras de las cárceles, perdonándoles si los enterraban. Que hacian hoyos grandes donde metian con garfios, arrastrando de 2 a 3000 cuerpos juntos, sin distinción, ni quitarles nada, y que a los que lo hacian ahorcaba luego don Miguel de Aguiar, regente de la Vicaría, que bubo vez que aborcó 30 juntos por encubridores de ropa apestada.

Y en medio de esta desdicha, cuentan una cosa rara (vol. I, p. 46).

En este texto, «esta desdicha» es la etiqueta con que se hace referencia a todo lo que está sucediendo en Nápoles: la peste, el levantamiento del pueblo, la enorme mortandad, la liberación de los presos, la falta de escrúpulos para saquear los cadáveres. Se trata, sin duda, de un encapsulador que introduce ya una valoración de los acontecimientos que condensa, valoración que no se encontraba en los textos de Almansa y que se aproxima al uso que del encapsulador se hace en el lenguaje periodístico actual.

También encontramos encapsuladores que se limitan a etiquetar metatextualmente, es decir, haciendo referencia al tipo de texto o acto lingüístico relatado:

(21) [...] Murió, en fin, el día y la hora que dijo, y tomados los papeles, decían varias profecías, y entre ellas que España perdería el otoño su flota; que Francia sería invadida por tres partes, y que se habia de morir un gran señor y Monarca, y que en España comenzarían las felicidades desde el año de 57, que sus prosperidades serían muchas, y otras varias cosas de este tono. Este pronóstico se trajo a España y se rieron de él, ya ahora se han acordado, viendo la pérdida de los galeones (vol. I, p. 321).

(22) El príncipe Tomás fue de parte del Rey de Francia a sacarle un hijo de pila al duque de Mantua, y de camino se dice a echar la guarnición del Casal, y que metieron franceses, volviéndose los dos a ver con el Rey. Esta nueva anda muy válida, y todos la creen, por ser contra nosotros (vol. I, p. 149).

(23) En Inglaterra han hecho concordia, liga y amistad con el portugués. Ya está aquí un tanto de ella. Es en esta forma: que el portugués no pueda vender su especiería ni drogas a nadie si no es al inglés, el cual se hace caja para repartirlas por su mano en toda Europa, y que pueda ir al Brasil y demás 
partes a cargar, pagando los precios y derechos en Lisboa, con que excusa el portugués de convoyar sus navíos y otros riesgos de pérdidas y tormentas. Ayúdanse el uno al otro; en particular ingleses lo han de hacer de vituallas y municiones, siempre que se les pidiere, y asimismo de navíos y gente, con que me parece que Portugal se ha rematado para siempre jamás. Estos tratados se concluyeron cuatro días después de haber degollado al hermano del embajador de Portugal (vol. I, p. 58).

La gran innovación que se observa en este texto en relación con el de Almansa y que, de alguna manera, anuncia lo que alcanzará pleno desarrollo en el s. XVIII es la presencia de encapsuladores con artículo ${ }^{18}$. En efecto, hasta ahora todos los ejemplos encontrados eran SSNN con la estructura 'demostrativo + sustantivo'. La presencia del demostrativo facilita cognitivamente la identificación del referente, pues indica precisamente proximidad en el cotexto de la información encapsulada. La aparición del artículo, en cambio, implica un esfuerzo inferencial por parte del lector a la hora de individuar el conjunto de hechos encapsulados y referidos por el SN.

(24) La armada que se apreta en Cádiz son 30 bajeles de guerra y 10 de fuego. Envió el conde de Molina un barco largo a tomar lengua de la del inglés, a tiempo que hacía lo mismo él para saber de la nuestra. Encontráronse los dos en el camino, y el nuestro rindió al contrario, que, traído a aquella ciudad, confesaron la gente que venía que estaban juntos turcos e ingleses, y que se habían convenido que la plata de la flota que se tomase había de ser para los ingleses, y la gente y bajeles para los turcos.

Sucedió otro caso notable. Envió un bajel muy bien armado con un capitán excelente, muchas armas y soldados escogidos para ver los navíos que estaban juntos. Llegó éste, pues, animosamente de noche, y metióse entre todos como quien se entra por su casa. Notó que tenía el inglés 28 navíos, y que 18 que había más eran de turcos, sin otros que daban carena y habían ido por vituallas. $\mathrm{Al}$ amanecer le reconocieron, y le tiró su capitana una pieza sin bala, y a tiempo que él se iba retirando, salieron dos navios de turco siguiéndole, alargándose todos mucho, de suerte que al cabo de dos horas le embistieron los dos, cada uno por su costado.

Estaba nuestra gente prevenida, metida toda debajo de la cubierta, con que $\underline{\underline{a}}$ primera ruciada fue en balde (vol. I, p. 165)

Repárese en que en todos los casos citados hasta ahora el encapsulador ocupa su posición temática prototípica en la que realiza la función cohesiva, a modo de bisagra, entre dos informaciones diversas: por una parte, se resume lo relatado anteriormente y por otra, se toma como punto de partida para iniciar una nueva información o para

\footnotetext{
18 No aparece ningún encapsulador con artículo en el texto de Almansa y son claramente minoritarios en el texto de Pellicer, que cronológicamente es anterior al de Barrionuevo, aunque en este trabajo hemos optado por alterar el orden en la exposición del análisis.
} 
resaltar un nuevo aspecto. Esto es particularmente evidente en casos como el citado «Y en medio de esta desdicha, cuentan una cosa rara» (p. 46), donde el encapsulador sirve de marco para una nueva anécdota ${ }^{19}$.

A pesar de todo lo señalado hasta aquí, el uso de deícticos metatextuales sigue siendo mayoritario:

(25) Por acá todo es doblones la moneda que corre, y se truecan con dificultad. Dícese ser la causa valer más que en Aragón ni en otros reinos. Hay poca plata también. Entiéndese haber en los puertos inteligencias para sacarla. Si esto pasa ahora que han venido las flotas, qué será por Navidad (vol. I, p. 48).

(26) De Badajoz se avisa que se guardan los tratos de paz con tanta puntualidad, que habiendo venido un portugués a la raya de Castilla, hurtó un pollino, y que yendo el dueño a quejarse, se le volvieron luego de contado, ahorcando antes que se fuese a su lugar el agresor. Todo esto denota querer cada uno guarda la paz inviolablemente (vol. I, p. 56).

(27) Dícese de Cataluña que el Francés había cortado 300 caballos nuestros y que no se le había escapado hombre, y que su Majestad ha ordenado al señor don Juan salga en busca del enemigo y choque con él, aunque se pierda, que después de lo de Puchardán parece que todo sucede al revés. Algo de esto debe de pronosticar el monstruo que ha aparecido (vol. I, p. 78).

(28) Hoy se le acaba el término a Lanuza. Está en la cárcel tan gordo, que hiende, diciendo que no se le da un cuarto de nadie; que su vida y honra es la de todo el Consejo. Con todo esto, los que sienten bien, juzgan que no escapará de privación de plaza para siempre y destierro de los reinos, que tiene contra sí 72 capítulos de cosas enormes y señores grandes le persiguen (vol. I, p. 109).

Pero a veces se recurre a otros elemento anafóricos, como los pronombres personales de tercera persona ${ }^{20}$, entre los que destaca «ello», elemento que, como es sabido, acabará funcionando como conector con el valor aproximado de 'es el caso

19 Por supuesto, sigue siendo frecuentísima la aparición de encapsuladores en posición remática, mucho más consolidada que el uso en posición inicial que aquí nos interesa especialmente. Véase, por ejemplo, el siguiente pasaje: «Todos los caminos están llenos de ladrones, particularmente el de Andalucía, donde andan de 20 en 20, de 30 en 30 y de 40 en 40 hombres a caballo, llenos de charpas, con seis y siete bocas de fuego desde Tembleque, Camuñas, Ocaña, corriéndolo todo. Traen caballos de 200 ducados. Presúmese ser de los mismos lugares. Roban a cuantos topan, y quitan de carros y coches cuantas mulas hallan. He estado con un hombre que cayó con otros en este trabajo, y me ha dicho [...]» (vol. I, p. 195)

20 A pesar de su indudable función cohesiva, no tenemos en cuenta los bien atestiguados pronombres personales en caso oblicuo, siempre anafóricos, del tipo «Así lo avisa al Rey mi primo» (vol. I, p. 83), «Hanlo juzgado todos a mal agüero» (vol. I, p. 83), puesto que por su carácter átono nunca ocupan la posición temática oracional. 
que' («Ello se ha de andar el camino que Dios quiere», Francisco Garau, El sabio instruido de la gracia, 1703, apud CORDE), valor que ya se adivina aquí:

(29) El pleito de la dueña aragonesa que por su gusto mataba a cuantos quería con unos polvillos que les echaba en la comida, de que la tienen probada, aunque con testigos singulares, 22 muertes, vino ayer al Consejo Real sobre si le darán tormento para mayor averiguación, o ejecutarán en ella sentencia de muerte, por no ponerse en contigencia de que, negando en el tormento, purgue todos los indicios. Ello es un pleito muy bellaco (vol. I, p. 93).

Aunque hemos aludido brevemente a ellos en el apartado anterior, queremos aquí prestar especial atención a una serie de términos que quizá empezaron funcionando como encapsuladores, pero que por tratarse de hiperónimos muy generales y fuertemente desemantizados, se aproximan, ya en el uso que de ellos se hacía en el s. XVII, a los deícticos metatextuales. Nos referimos a términos como «cosa», «hecho», «cuestión», «asunto»:

(30) En Castilla la Vieja andan bandadas de ladrones. Junto a Sepúlveda salieron a unos arrieros que traían tabaco, y escapándose uno, dió aviso al Corregidor, y acudiendo, prendió dos, y porque los ahorcó, más de cincuenta acometieron al lugar, donde hubo una de los enemigos, muriendo algunos y quedando otros descalabrados. Todas estas cosas son efectos de la guerra (vol. I, p. 108) ${ }^{21}$.

No obstante, este tipo de términos tiene en Barrionuevo un uso mucho más extendido en función catafórica: «Remato con una cosa graciosísima» (vol. I, p. 63), «Señor mío: las cosas de Madrid andan todas a Dios te la depare bueno» (vol. I, p. 100), «Terribles cosas se dice pretende el Rey en estas Cortes» (vol. I, p. 112), «He visto esta mañana una cosa galante de Roma» (vol. I, p. 124), «Una cosa notable diré aquí del descuido con que vivimos» (vol. I, p. 130) ${ }^{22}$.

${ }^{21}$ Un ejemplo de la prensa actual lo tenemos en «No se puede pedir la paz y al mismo tiempo ponerse abiertamente del lado de uno de los beligerantes, y si en estos momentos quisiera transformar en hechos sus declaraciones de buena voluntad, se daría cuenta de lo contraproducente que ha sido su actitud. Las cosas son demasiado graves para aplaudir los reflejos irreflexivos» ( $A B C, 22$ de julio de 2006, p. 4), donde evidentemente «reflejos irreflexivos» es otro encapsulador fuertemente valorativo en posición remática.

22 Con frecuencia Barrionuevo introduce en esta posición la valoración que hace de las noticias que relata a continuación: «Mis nuevas son como las perdices, apareadas, una buena y otra mala» (p. 131). Sin embargo, los comentarios más críticos suelen aparecer desgajados de la noticia, al principio o, con más frecuencia, al final de la misma y tienen cierto carácter gnómico: «Murió muy aprisa el teniente que dio garrote al criado del marqués de Cañete. Justo castigo del cielo que muera apresuradamente quien tanto se apresuró contra un inocente» (p. 94). He aquí otros comentarios: «Todos procuran subir, al paso que esta Monarquía va bajando» (p. 79); «Todo es comedia en Madrid, sin haber más firmeza en las cosas que en el aire que corre» (p. 91); «Este mundo todo es trazas, aunque no todas salen como se piensan» (pp. 148-149). No escasean los símiles denigratorios como éste: «Para que el gusano de seda no 
Un caso intermedio es el del «negocio» que puede interpretarse como un sustantivo a medio camino en su proceso de desemantización (cf. asimismo el ejemplo (18) de Almansa), según aparece en los siguientes pasajes:

(31) El Corregidor de Madrid se ha excusado de ir a Torrejimeno a lo de Lanuza. Buscan persona que lo haga. Su padre ha dado petición a la Junta en orden del alivio de prisioneros, guardas y cárcel, ofreciendo 6000 ducados de fianzas. Hanse reido de él, y hicieran lo mismo si ofreciera, según dice, cuanto tiene. El negocio es largo, y pienso lo estirarán cuanto pudieren, por si las incomodidades acabasen con él (vol. I, p. 83)

(32) Encontró don Francisco de Medrano, alcalde de la Corte, un oficial del Consejo de Estado, y yendo de ronda, que iba a firmar unos despachos. Quitóle el broquel, aunque le dijo quién era y a lo que iba, y que tenían licencia de Su Majestad para traer armas defensivas y ofensivas todos los de su Consejo, donde se quejó el día siguiente. El cual, habiéndolo consultado con el Rey, llamó al Alcalde y le dio de su orden una reprehensión poniéndole de vuelta y media. Contólo en la Sala, y de allí a cuatro o seis días, ofreciéndose otro encuentro por unas cuchilladas con otro Oficial de Estado, y dándole la casa por cárcel, en sabiendo que lo era, le metió en la de Corte en un retiro cargado de hierros y acudió el Consejo a Su Majestad, el cual mandó prender al Alcalde Corte como lo está al presente; y el Consejo Real no se ha apartado viernes y sábado, procurando resistir y consultar al Rey de que no está bien dar tanta mano a Consejo ninguno, aunque sea el de Estado, en materia que no quiere reconocer a nadie por superior de ninguna manera. El negocio es enconoso: veremos en qué para, que tiene de todo, a juicio de los hombres más cuerdos (vol. I, p. 313).

La ausencia de encapsuladores en posición temática en estos textos encuentra su explicación en el peculiar andamento sintáctico de las oraciones que componen las noticias de los textos de la primera mitad del s. XVII. Téngase en cuenta que se «buscaba sobre todo la eficacia informativa, por lo que en esas misivas no suele haber florituras ni esfuerzos estilísticos de ningún tipo: las noticias están expuesta de forma escueta» (Ettinghausen y Borrego 2001: 47). En efecto, como ya advertimos en anteriores trabajos (Borreguero y Octavio de Toledo 2003, 2004, 2006), los escritores de estos textos, en su afán de síntesis, privilegian la anteposición del verbo $^{23}$ a la

se muera al encapotarse el cielo y echar bravatas, así de truenos como de los rayos que arroja, el remedio único es tocar guitarras, sonar adufes, repicar sonajas y usar de todos los instrumentos alegres que usan los hombres para entretenerse. Esto acontece al Rey, que en los mayores aprietos sólo se trata de festines» (p. 153).

${ }^{23}$ No tenemos aquí en cuenta los verbos dicendi que suelen introducir las noticias, del tipo de «dícese», «avisan», «escriben», etc. y que, ya en los mencionados trabajos (Borreguero y Octavio de Toledo 2003, 2004, 2006), dejábamos al margen del estudio de la organización informativa 
especificación del agente, como se ve en estos ejemplos que son, sin duda, extremos, pero que nos dan una idea de hasta dónde puede llegar esta preferencia:

(33) Entró la duquesa de Osuna con grande acompañamiento, y no con menos la marquesa de Velada. Besó la mano a su majestad la provincia de Guipúzcoa, acompada de la mayor parte de su nobleza. Tuvo audiencia el gran canciller de Milán y despachósele después de algunos días [...] (Almansa, 2001[1621]: 192).

(34) Mató el Rey un lobo muy grande el otro día, y costóle de cebar para que viniese a sus manos, 18.000 reales, de diversos animales que le ponían vivos, sin perdonar asno viejo. Pusieron la cabeza de él en el jardín contra lor. Es como la de un caballo. Han ido muchos a verle, entre ellos un Patriarca, que dijo: "Aquí falta poner: «Costó esta muerte 18.000 reales»" (Barrionuevo, 1968[1655]: 118).

De este modo, se reduce el número de sintagmas nominales que ocupan la posición temática, que en textos posteriores suele reservarse para agentes destacados, para especificaciones circunstanciales y, con menor frecuencia, para los objetos de la acción que se relata.

Solo cuando gana claramente terreno la anteposición del agente en la estructura sintáctica e informativa de este tipo de textos podemos hablar de un auténtico desarrollo de los encapsuladores, como se observa en los relacioneros y gacetilleros de finales del s. XVII.

\subsection{Los Avisos de Pellicer}

En los textos de José de Pellicer sigue siendo habitual el orden de palabras comentado más arriba, con la anteposición verbal en gran parte de las oraciones, pero cada vez son más frecuentes aquellas cuya posición temática está ocupada por un SN, sea este el agente, el objeto o la circunstancia en que se produce la acción. En efecto, en este autor es difícil encontrar párrafos en los que todas las oraciones sigan el mismo patrón, como los que hemos extraído de las obras de Almansa y Barrionuevo. Se multiplican, consiguientemente, las posibilidades de aparición de encapsuladores temáticos.

La mayor frecuencia de encapsuladores redunda además en una mayor variedad de etiquetas, que se refieren ya mayoritariamente a acontecimientos, siendo mucho menor el número de las relativas a tipos de texto y actos lingüísticos ${ }^{24}$. He aquí algunos ejemplos:

(35) En Alemania andan algo más dichosas las armas Imperiales. Arnehim, que era Teniente General del Duque Elector de Saxonia, que estaba preso en

textual por considerarlos formas convencionalizadas de carácter epistémico que muchas veces no tienen más función que descargar al autor de la responsabilidad de lo referido.

${ }^{24}$ Con todo, debemos decir que «nueva»y «nuevas» siguen siendo los términos encapsuladores más frecuentes. Cfr. pp. 36, 37, 42, 52. 
Stokolmo, Corte de Suecia, con toda estrecheza, se escapó con una sutilísima cautela y se entró en Copenhague, Corte de Danenmark. Asiste el Emperador al Marqués Elector de Brandemburg, sobre restituirle en el Ducado de Pomerania; y en este intento tiene empeñado un gran trozo de exército en Galso contra la Reyna Niña de Suecia y a su General Bannier (p. 3).

(36) El Señor Cardenal de Saboya y el Príncipe Thomás entraron por el Piemonte. Ocupó el segundo a Chivás y otras Plazas. Llégoseles un buen golpe de gente de hasta diez mil hombres, con gran parte de la nobleza de Saboya, que llevan mal el gobierno de la Señora Duquesa madre, hermana del Rey de Francia. Esta invasión se cree ha de divertir mucho los progresos que tenían destinados esta campaña por el Lenguadoc y por Navarra [...] (p. 4).

(37) Nuevas diferentes han venido del Brasil, y contienen las más ciertas que el General Macareñas, que fue a llevar el socorro el año pasado a Fernambuco, no se quiso determinar de entrar de golpe sin reconocer el estado en que se hallaban los Holandeses, contra el parecer del Capitán Pimienta y otros Cabos; y esta remisión fue causa de derumbarse por aquel mar a parte donde calmaron $[\ldots]$ (p. 10).

(38) Don Sebatián de Contreras no ha querido venir de Tordesillas. Diéronle los gajes del Consejo de Hacienda; y han aceptado su renunciación. Dicen que todos estos retiros los causa la sed de ser título (p. 20).

(39) A esta Consulta respondió su Magestad lo siguiente: Yo apruebo todo esto y os doy facultad para lo demás que ajusteredes con el Conde, quitando, ó añadiendo, ó enmendando, y acabad, porque es ya tiempo y ha pasado mucho de él. En esta conformidad ${ }^{25}$ le han dado ya los parabienes Madrid y otras Ciudades, y se van ajustando los despachos de estas mercedes, las mayores que ha hecho Príncipe á Valido alguno (p. 23).

(40) Por carta del Señor Marqués de los Vélez, se ha sabido que el Señor Cardenal Infante metió socorro en la Plaza de Hedin, peleando antes con el exército de Francia, en que degolló seis mil Franceses, prendiendo al General y demás Cabos. De esta victoria no ha llegado aviso de Flandes, aunque se tiene por cierta (p. 29).

Los encapsuladores que dejan traslucir la visión del narrador son también más frecuentes, por lo que este mecanismo se va definiendo como locus de apreciación subjetiva de los hechos referidos. En ocasiones, el encapsulador aparece como complemento nominal de otro término, pero ocupando junto con éste la posición temática:

${ }^{25}$ Repárese en que este encapsulador en el sentido en que aquí es usado ha sido remplazado en la lengua actual por la locución 'conforme a esto', que selecciona un deíctico metatextual. 
(41) Esta noche misma cruzaron cruelmente la cara á Juan Varela, sastre del Rey, añadiéndole dos estocadas, y juntamente amaneció herido de muerte (pues le enterraron el Viernes) Gregorio de Ervás, oficial de libros de la Contaduría mayor, mozo de grandes alientos. Los puestos tan distintos de estas dos desgracias dieron a entender que eran diferentes los motivos (p. 28).

(42) Dícese que en una Ciudad de España, sin saberse qual es fijamente (unos cuentan que en Sevilla, otros que en Valladolid), tenía concertado verse un galán de voz con cierta Religiosa que festejaba, abuso mal permitido en estos Reynos. Entró de noche y, al llegar á la celda el hombre, oyó grandes alaridos y gritos de un niño. El horror del pecado que iba á cometer le hizo volver atrás y salióse (p. 60) ${ }^{26}$.

Un caso claro de etiquetación conceptual lo tenemos en (46), donde la redacción de un memorial es definida como un servicio particular al rey:

(43) Sin embargo la Diputación ha embiado vn Diputado que ha dado vn Memorial a Su Magestad, representándole los Inconvenientes que se pueden ofrecer cada día, si no se moderan las Demasías de los Soldados. Por este servicio particular ha hecho merced Su Magestad a Don Antonio Pellicer de dos Escudos de Ventaja sobre qualquier sueldo (p. 97).

El que más arriba hemos llamado «efecto bisagra» del encapsulador cobra especial relieve cuando el término utilizado es polisémico, seleccionando un sentido como resumen de lo anterior y otro como tema de lo que viene a continuación. Creemos que el aprovechamiento de la duplicidad de significados de un término en su función de encapsulador es más propio de los textos de esta época que de los actuales, aunque no descartamos que se encuentren ejemplos también en la prensa de hoy. En el texto que reproducimos a continuación, el sustantivo «milagro» se refiere tanto al suceso, el disparo a don Diego de Pareja, como al escrito en que se relata el suceso ${ }^{27}$. En este último sentido, se afirma que «el milagro [está] colgado en la Capilla de la Virgen», pero «el milagro» es a su vez un designador de lo sucedido, pues parece que a los ojos de Pellicer y de la sociedad a la que pertenece, no puede explicarse de otro modo lo acontecido, si no por intermediación divina:

(45) A Don Diego de Pareja, Caballero del Orden de Montesa, hermano de Don García de Pareja, que fue un poco de tiempo valido del Señor Cardenal Duque de Lerma, y Embaxador en Francia y Flandes, estando rezando como acostumbraba á deshora en la puerta de la Merced á nuestra Señora de los

\footnotetext{
26 Téngase en cuenta que en este texto el intento del joven está valorado no solo en el encapsulador, sino también en la aposición «abuso mal permitido en estos Reynos», que es otro de los lugares tradicionales de introducción de juicios y comentarios del autor en el lenguaje periodístico. Ver nota 17.

27 Véase también el caso de «pronóstico» que aparece en (21) de Barrionuevo, donde puede descubrirse una referencia al pronóstico como género literario.
} 
Remedios, viendo cuidadosos dos hombres, se levantó a un tiempo que le dispararon una pistola. Diéronle en los pechos con una bala que, pasándole la ropilla, quedó pegada á una Imagen de papel de nuestra Señora de los Remedios que tenía en el pecho. Los agresores están presos, el milagro_colgado en la Capilla de la Virgen. La estampa y la bala llevaron a los Reyes (p. 28).

Por supuesto, no faltan los encapsuladores desemantizados a los que aludíamos en apartados anteriores, que no se reducen al habitual «cosa»:

(46) Hablar de la justicia o falta de derecho de Francia, que son los exes sobre que se mueve toda esta monarquía militar y política no es de mi propósito, pues de este asunto corren ya libros enteros (p. 1).

como tampoco los que hemos denominado encapsuladores metatextuales:

(47) En Italia dicen que el Señor Príncipe Tomás ha desbaratado otro nuevo Socorro que embiava Madama la Duquesa de Saboya a la Ciudadela de Turín. Este aviso aún está en borrón. Espero el Correo que lo certifique. No hay otra novedad digna de Escritura. (p. 82).

Sin embargo, la característica más destacada de este texto, que será común también a los posteriores, es el uso de encapsuladores para referirse a fragmentos de texto cada vez más extensos. Dado que no podemos reproducir, por razones de espacio, los más llamativos, que superan la página y media, nos contentaremos con un caso intermedio, para que el lector pueda hacerse una idea:

(48) Llegó el Príncipe de Condé, Generalísimo de las armas de Francia y Gobernador de ellas el Duque de Halwin. Después de la toma de Oppoli, se fortificó en Clayra comenzó á batir á Salsas, á 10 de Junio, con veinte y quatro mil Infants y quatro mil Caballos. Los Franceses corrieron con la Caballería hasta Periñán. Salió Don Alvaro de Quiñones, Teniente General, y le degolló un buen trozo de caballos, escapando mal herido el Duque de Halwin, habiendo perdido el caballo, muriendo el Conde de Brión, hermano del Duque de Pentheure, el Conde de Bercehe, un Marqués que enterraron en la Merced, trayéndole mal herido, el Señor de San Clemente, el Gobernador de Mompeller y el Abad de San Gil, con otros Mosieures en cantidad de quarenta. Retiró Don Antonio Pellicer de Tovar, Capitán de caballos, unas Imágenes de Christo y su Madre, que halló arcabuceadas, no lexos de la parada, terrerno que defendía con quinientos Arcabuceros. Con estas nuevas que llegaron el Sábado, estaban alborozados todos los Ministros [...] (p. 33).

Asimismo son frecuentísimos los encapsuladores intertextuales. Téngase en cuenta que los Avisos de Pellicer se publicaban semanalmente y esta continuidad garantizaba la familiaridad con las noticias por parte de los lectores, lo que permitía incluir una serie de referencias cruzadas a los avisos anteriores e incluso adelantar algo de los futuros («Esperánse por instantes grandes avisos, así de mar como de tierra» (p. 43)). 
Entre estas referencias están sin duda los sintagmas que abren una noticia recordando lo que se ha narrado en otra anterior.

(49) La misma noche que envié el aviso de la mejoría del Señor Marqués de las Navas, esa misma murió. Tan cerca está de la buena nueva la mala. Queda enfermo de peligro el Señor Conde de Aguilar (Avisos de 8 de noviembre de 1639, p. 62)

Por la muerte del Señor Marqués de las Navas, parece que pretende aquel Estado el Señor Marqués de Mirabel y que quiere intentar no sucedan hembras (Avisos de 15 de noviembre de 1639, p. 64) ${ }^{28}$.

En definitiva, la obra de Pellicer supone una ruptura con el tipo de prosa de los avisos y relaciones. Las noticias adquieren una autonomía y un grado de elaboración desconocidos hasta el momento, que anticipan el que tendrán en las gacetas. El mayor desarrollo narrativo propicia, sin duda, la aparición de encapsuladores en el interior de la noticia, si bien todavía son muy frecuentes los encapsuladors intertextuales.

\subsection{Las Noticias Extraordinarias del Norte de Pedro de Huarte}

En la gaceta donostiarra vemos confirmadas las tendencias que se prefiguraban en Pellicer: a) un incremento considerable del número de encapsuladores en el cuerpo de la noticia; b) una mayor presencia de términos de naturaleza eventiva en función de encapsulación, que hacen referencia a fragmentos discursivos cada vez más extensos y que se sitúan con frecuencia en la última oración de la noticia, donde se concluye con una pequeña síntesis de lo expuesto; y c) la consolidación del encapsulador con artículo, que había hecho su aparición en los textos de mediados de siglo.

(50) De Possega se escribe que avendo los Turcos de Gradiska sobre aviso de que tropas Cesareas marchavan azia Esseck con viveres, y municiones pasado su

\footnotetext{
${ }^{28}$ Se siguen manteniendo los encapsuladores en posición remática, que son muchas veces los mismos que hemos encontrado en los ejemplos anteriores: «El obispo de $\mathrm{C}[\mathrm{o}]$ menge, Francés, que tiene lo espiritual del Val de Arán en España, con achaque de visitar su Obispado, entró con más gente de la acostumbrada en otras visitas; y ésta la iba dexand[o] en los lugares por donde pasaba. Conocieron el intento los Araneses y prendieron al Obispo y á todos los de su séquito» (p. 25).

Asimismo siguen siendo muy usados los deícticos metatextuales. Para no caer en una prolijidad innecesaria ofrecemos solo un ejemplo: «Dícese que Su Santidad con toda eficacia propone vna Plática de Paz o Suspensión de Armas. Y que para esto ha despachado tres Legados [...]» (p. 105) . También merece la pena mencionar un uso particular del relativo que tiene como referente un acontecimiento, semejante al uso actual, pero que aparece en los textos tras puntuación fuerte: «Y cómo dos Capuchinos de Girona entraron pisando brasas y llamas, sin quemarse ellos ni los Abitos i sacaron la Custodia, donde hallaron 20 formas consagradas poco mayores que vn ochavo de Castilla, de color de papel quemado, reducidas a tanta pequeñez por el incendio, sin bien conservavan los Caracteres Impressos. Lo qual sabido por el Señor Don Fray Gregorio Parcero, Obispo de Girona [...]» (pp. 123-124).
} 
puente con intento de acometer a los nuestros, y aviendo avanzado en numero de 3500. hombres en 23. del passado cerca de Cernick. El Coronel Baron de Arizaga, y el Sargento mayor Bolan salieron con la Cavalleria, y parte de la Infanteria, y acometieron à los Infieles con tanto valor, que los obligaron ha huir, $y$ abandonar á los Geniçaros, de los quales 500. quedaron muertos sobre la plaça y 150. prisioneros, entre ellos 4. Agas, ó Capitanes de Cavallos, el Comendarte de los Geniçaros, y el hijo del Baxa de Gradiska los Estandartes, y tambores ganados al enemigo los embió el Baron de Arizaga al General Caparar, el combate fue muy reñido, y duro mucho tiempo; solo de nuestra parte ha perecido 66. hombres. (03.05.1688, p. 143)

(51) Se ha sabido que la guarnición, y vezinos de esta plaza avian resuelto de rendirse, si pudiessen obtener una capitulacion semejante á la que fué concedida á la guarnicion de Agria, en la conformidad, que les avia propuesto de parte del Cardenal Colonitz; pero que el Baxa no venia en esto, por hallarse resuelto de resistir asta la ultima extremidad: que los principales de la Milicia se avian irritado, de manera, que avian tomado las armas tumultuariamente contra sus oficiales, y que aviendo llegado à las manos fueron muertos asta catorze. Esta desorden se confirma por la resolucion, que han tomado los Imperiales, de marchar azia esta plaza, no dudandose, que la guarnicion solo espero á este pretesto para precisar al Baxa à capitular (10.02.1688, p. 123).

(52) Tuvose otro nuevo consejo de guerra, donde se resolvio dar una arma falsa de noche para poder divertir los puestos, haziendo diferentes tentativas mantenidos de la artilleria, y morteros; mientras un cuerpo de 6000. hombres que marchavan debaxo del mando del Conde Serini, General de las tropas Babaras, assistido de los Generales Steinau, Aspremont, y del Conde de Fustemberg passase en varcos à un puesto distante de donde estava la fuerza mayor del enemigo. Esta accion se executo con orden, pues atravesaron el rio sin aver sido sentidos, [...] (20.09.1688, p.174).

No encontramos, sin embargo, encapsuladores valorativos, debido sin duda a que la principal fuente de información de Huarte eran las cartas del ejército imperial en las que se narraban muy escuetamente los hechos militares y se ofrecían con la misma parquedad otros datos de interés relativos a las campañas bélicas. No se permite el editor vasco añadir ningún comentario a estas informaciones, desapareciendo por tanto todo rastro de subjetividad, como ya ocurría en buena medida en los Avisos de Pellicer, en las que la conciencia del informador imparcial y su propósito de contar el presente como parte de una crónica histórica habían terminado por eliminar el tono licencioso y burlesco de Barrionuevo y los retóricos encomios de Almansa.

No obstante, la ausencia de valoración explícita de los hechos no implica que a determinados fenómenos o hechos no se les adjudique una etiqueta que los clasifica según la interpretación que de ellos hace el narrador. Así, una humareda es considerada una «señal» y el traslado a Nápoles de una parte de la población de Malvasía es un «medio» para terminar con los acuerdos establecidos con el Bajá y sus oficiales: 
(53) El dia 10. por la mañana hizo Su Alt. poner en marcha el exercito azia Belgrado en la mejor forma que le permitia el terreno con el designio de atacar á los Turcos en las fortificaciones que tenian, debaxo de la artilleria de esta famosa fortaleza, que ceñida de los rios Savo, y Danubio á las espaldas á este ultimo, y la Villa, y sus reparos con buena defensa de paliçada de maderos, y con un buen fosso alrededor, á distancia de una legua se advertió en una espesissima bumarada, que pareciò en el ayre, que los Turcos hizieron; por donde conocieron que los enemigos, no estavan en disposicion de esperar à los Imperiales. Con esta señal apretaron la marcha del exercito (20.09.1688, p. 175, p. 175).

(54) Añadiendo, que sean compreensos los que de 15. asta 60. que no se hallasen infestados del Contagio, y los que tuviessen edad con sus mugeres, y criaturas, passassen á Napoles de Malvasia; porque no siendo capaces de servicio alguno, lo fuessen á lo menos para consumir quanto antes los viveres de esta plaça, y por este medio la inteligencia que mantenian con el Baxà, y oficiales de la guarnicion de esta plaça, y la de Negroponte se interrumpiessen [...] (17.05.1688, p. 146).

Además encontramos todos los otros tipos de encapsuladores ya mencionados en mayor número que en los textos anteriores. Tanto los que etiquetan un acto lingüístico o un género discursivo:

(54) Se ha sabido también por las cartas de Esclavonia, que un gran trozo de guarnición turca de Gradisca aviendo passado el Savo, ha saqueado, y abrasado algunos Villages, en una correria que ha hecho asta las puertas de Possega, llevandose mas de 200. Paysanos prisioneros consigo, por esta noticia se han embiado á la Esclavonia nuevas tropas con orden á todos los Generales de velar cuidadosamente sobre los movimientos de los enemigos (10.02.1688, p. 124).

(55) Avisan de Roma, que el Beatissimo Padre se ocupa en persuadir á su Corte, y a toda la tierra, que nada cederá de lo que ha emprendido, y que el Trono de San Pedro, nada teme á las armas temporales: en esta consideración ha mandado hacer hazer una medalla de oro [...] (08.03.1688, p. 129)

como los intertextuales, como puede verse en (56), donde es especialmente evidente la continuidad entre los distintos sucesos narrados:

(56) La surpressa de Radzk, por el Baron de Tungen, de que se ha hablado, en la antecedente ${ }^{29}$, sucediò en la manera siguiente $(17.05 .1688$, p. 145)

Así como los que hemos llamado encapsuladores de objeto:

${ }^{29}$ No se conserva, sin embargo, ninguna mención a la toma de esta ciudad en los textos que nos han llegado. 
(57) [...] y que dicho General Carrafa negoció tambien, de que en la proxima campaña los Transilvanos asistirán á los Exercitos Cesareos con todo genero de viveres, pan, carne, y bino por dinero, y que las provisiones baxaran sobre el referido rio $[\ldots](17.05 .1688$, p. 144)

No desaparecen los deícticos metatextuales, si bien se modera su uso respecto a textos como el de Barrionuevo:

(58) Las cartas que escriven de Debresein, en la Alta Ungria, de veinte y ocho del passado traen las particularidades siguientes de la entrepressa, que se ha hablado; de cómo el General de vatalla Baron de Heisler formó contra el Rebelde Conde Tekely, quin haze algunos dias bino a atrincherarse en un Village, sobre el Rio Berirzio, á media legua de la plaza del Gran Varadin, con tres mil hombres, que pudo juntar de Ungaros, Tartaros, y Turcos gente falza, y vagamunda; procurava con todo esfuerço el subsistir estas tropas, con solo las correrias, y robos, que comenzaron hazer por todos aquellos contornos. Esto dio motivo á dicho Generla Heisler para marchar a veinte y tres a sus atrincheramientos con quatro Regimientos de Cavalleria (22.03.1688, p.131).

(59) Despues que bolvió de Raab el Principe Herman de Baden, Presidente del Consejo de Guerra de su Mag. Imp. han llegado dos Turcos, y tres Racianos de Alba Real; y han declarado, que desertaron voluntariamente aquella plaza, y que algunos dias antes que saliessen los Genizaros, que estavan de guarnicion llevaron a fuerza de Armas quanto hallaron de provisiones de las principales casas de la plaza; esto hazia presumir, que muy presto podian acontecer mayores desordenes [...] (19.04.1688, p. 138).

y además aparecen integrados en textos más elaborados y cohesionados mediante varios mecanismos de encapsulación:

(60) Por sus respuestas se ha savido, que el exercito Infiel seria de 25 y. hombres [...]. Que el exercito Otomano no avia recebido pagas algunas despues de la eleccion del nuevo Gran Señor, por lo qual, no estavan muy gustosos, y por noticias que un correo trujo al campo de que serian pagados por entero, que para esto_venia el dinero en camino, conque se apaciguaron: y finalmente, que todos los campos asta Andrianopoli se hallavan desolados de forraje, y que no ses podia hallar cosa alguna para la subsistencia de su cavalleria.

Con estas, $y$ otras noticias, que se dieron al Serenissimo Elector de Bavioera hizo juntor Consejo de guerra [...] (20.09.1688, p. 173).

En (60) encontramos diversos procedimientos anafóricos de cohesión. Además del deíctico metatextual «esto» y del encapsulador «con estas, y otras noticias», aparece un relativo «lo qual» $\mathrm{y}$ un conector discursivo «con que» en pleno proceso de gramaticalización (Girón 2004), conservando todavía «que» reminiscencias de su función de pronombre relativo, cuyo antecedente serían las noticias que trajo un correo al campo de que los soldados serían pagados y de que el dinero estaba de camino. Por tanto, la mayor presencia y la evolución de los encapsuladores en los 
textos periodísticos no es en ningún caso un fenómeno aislado, sino que forma parte de un proceso más amplio de desarrollo de elementos anafóricos que contribuyen a la mayor cohesión de textos complejos.

\section{CONCLUSIONES}

A la luz de los datos que hemos presentado en este trabajo podemos confirmar nuestra hipótesis de que la gestación del lenguaje periodístico implicó el afianzamiento de una serie de mecanismos de cohesión, entre los que se encuentran los encapsuladores. En efecto, en nuestro recorrido por el s. XVII, desde las cartas de Almansa hasta la gaceta de Huarte, hemos podido comprobar que se produce un aumento considerable de los encapsuladores y, muy especialmente, de los que ocupan la posición temática y que, por tanto, contribuyen de forma decisiva a la organización informativa textual.

Esto conlleva un debilitamiento de los deícticos metatextuales, pues los encapsuladores no solo adquieren mayor presencia en los textos sino que van cobrando mayor peso léxico, y en algunos casos introducen elementos valorativos que anuncian ya el desarrollo que tendrán en el lenguaje periodístico a partir del s. XIX. Asimismo, se observa una progresiva disminución de los encapsuladores de dictum, así como de los hiperónimos desemantizados o palabras generales que recogen un hecho concreto. Por otra parte, abarcan segmentos textuales cada vez más extensos, al mismo tiempo que desaparece paulatinamente el encapsulador intertextual, reflejándose así la progresiva diversificación y amplitud del público lector, con el que poco a poco el periodista va perdiendo complicidad, lo que le obliga a un ejercicio de explicitación lingǘstica que queda reflejado tanto en el cambio de andamento sintáctico que supone el desarrollo léxico de las posiciones temáticas ${ }^{30}$, como en el recurso a un abanico cada vez más amplio de mecanismos de cohesión, algunos de ellos resultado de procesos de gramaticalización a partir de construcciones de relativo.

\footnotetext{
${ }^{30}$ Nos atrevemos aquí a sugerir que quizá uno de los posibles factores que influyeron en los paulatinos pero visibles cambios hacia un patrón imperante en el orden de palabras de las oraciones que van conformando los textos periodísticos parece haber sido la tarea de adaptar textos procedentes de otras lenguas desempeñada por muchos de estos primeros periodistas. Ya Ettinghausen y Borrego (2001: 17) apuntaban a la influencia que pudo haber ejercido en Almansa, durante su estancia en Italia, el conocimiento y contacto con las redes informativas que se estaban organizando en el país vecino. Recordemos que en Italia nacen las primeras gazzette y que este italianismo designará las relaciones periódicas de noticias que, desde finales del s. XVII, se publican en nuestro país. En efecto, las primeras publicaciones verdaderamente periódicas nacen en España como recopilaciones y traducciones de noticias aparecidas en las gacetas publicadas fundamentalmente en Flandes y en Italia. Esta influencia de los textos periodísticos extranjeros, que eran recopilados y traducidos al español o bien vueltos a redactar para conformar las gacetas nacionales, es particularmente visible en la obra de José de Pellicer.
} 
Todo lo cual es claro indicio, como señalábamos más arriba, del salto cualitativo del pre-periodismo al periodismo de masas dieciochesco, dirigido ya a un público anónimo, que puede tener interés por cada noticia del periódico en particular (y no solo por el conglomerado de "preñeces" que ofrecen los autores del XVII) y es capaz de gestionar textos informativamente densos.

De hecho, nuestras primeras incursiones en el siglo XVIII nos han confirmado la continuidad de estas líneas evolutivas, tanto en lo referente al carácter crecientemente valorativo de los encapsuladores:

(61) No se puede ponderar la fiereza con que los Ministros Othomanos han despreciado las proposiciones que se les hizo para volver à una nueva Negociacion, y ajustar la Paz con las Potencias Christianas [...]. Se sabe que la mayor parte de los Ministros del Divàn son inclinados à la Paz, pero ninguno ossa el declararse, por temor del Pueblo, que absolutamente quiere la Guerra. En este aprieto hace la Puerta sus mayores esfuerzos para salir con honor de este embarazo (Mercurio histórico y politco, 5[mayo 1783])

como en la propia forma en que se presentan estos, crecientemente encabezados por el artículo, lo que obliga al lector, como dijimos, a un esfuerzo de inferencia mayor, pero también subraya la unicidad (uniqueness) del sintagma encapsulante:

(62) En cumplimiento de la oferta hecha en el Plan de dar noticia de las diversiones honestas, que ocurriesen semanalmente en esta Ciudad, y en consequencia de haberla dado de varios refrescos y bayles de consideracion, debí hacer mencion en el Diario N.2 de los que dio á la Novia del Sr. D. Germano de Salcedo, su Padrino el Señor Don Joseph Colon de Larreategui en la noche del 4. del corriente. La omision fue efecto de debilidad [...] (José de Beristáin, Diario Pinciano, p. 49).

En este sentido, el desarrollo de los encapsuladores puede posiblemente concebirse como un síntoma más (cf. Borreguero y Octavio de Toledo 2003, 2004, 2006) de elaboración intensiva (intensiver Ausbaun ${ }^{31}$ ) en el seno de esta tradición (o género) aún naciente en el Seiscientos que es la noticia periodística.

31 La distinción entre elaboración intensiva y extensiva, que tiene cierto desarrollo en la lingüística alemana (desde su introducción en Kloss 1967 y Kloss 1978 hasta hoy: véase Haarmann 2004), surge en el ámbito de los estudios sobre oralidad y escritura, en los que ambos tipos de elaboración se entienden como modos diversos en los que se produce el paso desde una lengua oral hasta una lengua escrita. Se denomina elaboración intensiva al desarrollo de recursos expresivos de una modalidad lingüística para responder a las exigencias de la distancia comunicativa (López Serena 2007: 1003). En este sentido se oponen a la elaboración extensiva, o creación de nuevas tradiciones discursivas propias de la distancia concepcional (para la noción de tradición discursiva, véase ahora Kabatek 2006; para su relación con la inmediatez / distancia comunicativa en sentido concepcional, véase Koch / Oesterreicher 1990 [2007]). Algunos ejemplos de elaboración intensiva son la progresiva diferenciación entre las conjunciones hipotácticas y las preposiciones, las funciones metacomunicativas en relación 
Antes de finalizar, creemos que es necesario intentar al menos dar una explicación de las importantes diferencias observadas entre los textos de Pellicer y los de los otros autores aquí estudiados. En Pellicer se da, con toda evidencia, un tratamiento más moroso de cada noticia. Aunque ocasionalmente se acumulan, como en los demás autores, pequeñas series de noticias casi telegráficas, la dispersión es menor en los Avisos del aragonés, donde apenas se refieren sucesos particulares o actos ceremoniales, y donde tampoco, por otra parte, se reproducen discursos ajenos en estilo directo con la amplitud que, por ejemplo, en Almansa. Unos pocos grandes temas (operaciones militares de la Guerra de Treinta Años, rebeliones de Cataluña y Portugal) ocupan la mayor parte del espacio y tienen, además, una gran continuidad de aviso en aviso.

En la exhaustividad detallista, en el acopio de materiales escritos y la discriminación de las fuentes -Pellicer posiblemente maneja un mayor número de fuentes escritas que Almansa o Barrionuevo ${ }^{32}$, y también da menor cabida y crédito al rumor, al tiempo que rara vez se nos presenta a través del propio texto, a diferencia de sus colegas, como un 'yo' perseguidor de noticias-, en el menor subjetivismo y en los atisbos de análisis causal de los hechos presentados se adivina al cronista que fue Pellicer, al erudito también, de formación más sólida que los inquietos Almansa y Barrionuevo, que tiene el prurito de construir una obra con un alto grado de coherencia interna, incluso cuando aborda la crónica noticiosa, lo que acaba aproximando la "textura" de los Avisos a la de unos anales historiográficos al modo de Ferreras o Bacallar.

Pellicer reconoce la importancia de la autonomía de la noticia, a la que dota de un desarollo y de unos límites o perfiles nítidos -y por tanto de una autorreferencialidaddesconocidos para sus colegas, más interesados por satisfacer de modo rápido y atractivo (además de personalmente ventajoso) el ansia de novedades de sus destinatarios que por ofrecer una visión histórica a través de las noticias narradas. Si, como dice López de Zuazo (tomando precisamente a Pellicer como ejemplo) «a lo largo del siglo XVII, las relaciones son complemento de los libros» (López de Zuazo 2005: 398), los Avisos del zaragozano, aunque formalmente no pierden su peculiar estatuto «entre relación y carta» (Étienvre 1996), se perfilan también como una suerte de apéndice de la historiografía, adquiriendo así el tratamiento de la noticia, también

con la estructura interna del texto que adquieren determinadas expresiones (los llamados conectores metacomunicativos) o los procesos léxicos que dan lugar a una distinción entre lenguajes de especialización y lenguajes no especializados en determinados ámbitos socioprofesionales. Parece claro, a la luz de nuestros datos, que la historia de los encapsuladores en las crónicas periodísticas testimonia una elaboración intensiva de esa tradición a lo largo del siglo XVII, pero carecemos de datos suficientes para establecer si se trata de una evolución autónoma o fruto de un trasvase desde otras tradiciones de la distancia comunicativa.

32 V. nota 29. 
en lo lingüístico, la atención y la dignidad propias de unos textos tradicionalmente más elaborados.

\section{TEXTOS FUENTE}

A. Almansa y Mendoza, «Cartas», Obra periodística, ed. de Henry Ettinghausen y Manuel Borrego, Madrid, Castalia, 2001.

J. de Barrionuevo, Avisos (1654-1658), ed. de A. Paz y Melia, Madrid, Atlas, 1968.

J. de Beristáin, Diario Pinciano: primer periódico de V alladolid (1787-88), ed. de C. Almuiña, Valladolid, Simancas Ediciones, 1978.

P. de Huarte, Noticias Extraordinarias del Norte en J. Díaz Noci y M. Hoyo Hurtado (eds.), El nacimiento del periodismo vasco. Gacetas donostiarras de los ss. XVI y XVIII, Donostia, Eusko Ikaskuntza, 2003.

Mercurio histórico y politico, Madrid, Imprenta del Reino, 1738.

J. de Pellicer de Tovar, Avisos, ed. de J.-C. Chevalier y L. Clare, notas de J. Moll, Paris, Éditions Hispaniques.

\section{REFERENCIAS BIBLIOGRÁFICAS}

S. Azpiazu, Las estrategias de nominalización, Frankfurt, Lang, 2004.

M. Barra Jover, "Cambios en la arquitectura de la prosa española y romance: sintaxis y cohesión discursiva por correferencia nominal”, Revista de Filología Española 87:1, 2007, pp. 7-43.

M. Borreguero Zuloaga, "La progresión temática textual: algunos problemas pendientes”, en M. Vyllandre Llamazares (ed.), Actas del V Congreso de Lingüística General, Madrid, Arco / Libros, 2004, pp. 445-458. -- "Progresión temático-remática y organización informativa textual: convergencias y divergencias", en Casado Velarde, M. et al. (eds.): Análisis del discurso: lengua, cultura, valores, Madrid, Arco/Libros, vol. I, 2006a, pp. 205-220.

- "Naturaleza y función de los encapsuladores en los textos informativamente densos (la noticia periodística)", Cuadernos de Filología Italiana, 13, 2006b, pp. 73 95.

M. Borreguero Zuloaga y Á. Octavio de Toledo y Huerta, “Aportaciones del análisis del discurso a la historia de la lengua. La organización informativa textual", Res Diachronicae. Anuario de la Asociación de Jóvenes Investigadores de Historiografía e Historia de la Lengua Española, 2, 2003, pp. 524-533.

-- "La organización informativa en los textos periodísticos del s. XVIII: el Diario Pinciano", Res Diachronicae, 3. Estudios sobre el siglo XVIII. I Jornadas Monográficas de la Asociación de Jóvenes Investigadores de Historiografía e Historia de la Lengua Española, www.resdi.com, 2004, pp. 77-106.

"La crónica de sucesos (ss. XVII - XIX). Evolución y desarrollo de la organización informativa textual", Actas del VI Congreso Internacional de Historia de la Lengua Española, Madrid, Arco/Libros, 2006, pp. 2653-2667. 
W. D’Addio Colosimo, "Nominali anaforici incapsulatori: un aspetto della coesione lessicale", en T. De Mauro, S. Gensini, S. Piemontese (eds.): Dalla parte el ricevente: percezione, comprensione, interpretazione. Atti del XXVI Convegno Internazionale di Studi della Società Linguistica Italiana, Roma, Bulzoni, 1994, pp. 143-151.

J. Díaz Noci, y M. Hoyo Hurtado, "Estudio preliminar", en El nacimiento del periodismo vasco. Gacetas donostiarras de los ss. XVI y XVIII, Donostia, Eusko Ikaskuntza, 2003, pp. 13-118.

J.-P. Étienvre, "Entre relación y carta: los avisos", en H. Ettinghausen et al. (eds.), Las relaciones de sucesos en España : 1500-1750 : actas del primer Coloquio Internacional, Alcalá de Henares, Universidad de Alcalá, 1996, pp. 111-122.

H. Ettinghausen, "Informació, comunicació i poder a l'Espanya del segle XVII", Manuscrits, 23, 2005, pp. 45-58.

H. Ettinghausen, y M. Borrego "Prólogo" e "Introducción”, en A. de Almansa y Mendoza, Obra periodística, ed. de Henry Ettinghausen y Manuel Borrego, Madrid, Castalia, 2001, pp. 11-13 y pp. 15-128.

A. Ferrari, "Aspetti semantici e informativi della nominalizzazione sintagmatica", en C. Marello y G. L. Beccaria (eds.), La parola e il testo. In onore di Bice Mortara Garavelli, Alessandria, Edizioni Dell'Orso, 2002, pp. 179-204.

J. L. Girón Alconchel, "Gramaticalización de los marcadores del discurso e historia de conque", Lexis, 28:1-2, 2004, pp. 157-198.

H. Haarmann, "Abstandsprache - Ausbausprache", en U. Ammon et al. (eds.), Sociolingustics / Soziolinguistik, vol. I, Walter de Gruyter, Berlín / Nueva York, 2004, [2a ed. revisada y ampliada], pp. 238-250.

H. Jansen, Densità informativa. Tre parametri linguistico-testuali. Uno studio contrastivo inter-ed intralinguistico, Copenhagen, Museum Tusculanum, 2003.

J. Kabatek, "Tradiciones discursivas y cambio lingüístico", en G. Ciapuscio et al. (eds.), Sincronia y diacronía de tradiciones discursivas en Hispanoamérica, Frankfurt / Madrid, Vervuert / Iberoamericana, 2006, pp. 151-172.

H. Kloss, "Abstand-languages and Ausbau-languages", Anthropological linguistics 9, 1967, pp. 29-41.

H. Kloss, Die Entwicklung neuer germanischer Kultursprachen seit 1800, Düsseldorf, Pädagogischer Verlag Schwann, 1978.

P. Koch y W. Oesterreicher, Gesprochene Sprache in der Romania: französisch, italienisch, spanisch, Tübingen, Niemeyer, 1990 [trad. esp. de Araceli López Serena: Lengua hablada en la Romania: español, francés, italiano, Madrid, Gredos, 2007].

A. López de Zuazo, "Relaciones y papeles varios del siglo XVII, compañeros de periódicos", Estudios sobre el Mensaje Periodístico 11, 2005, pp. 393-406.

A. López Serena, "La impronta estructuralista de las escuelas de Tubinga y Friburgo. Presente, pasado y futuro de la lingüística de las variedades alemana”, en Roldán Pérez, A. et al. (eds.), Caminos actuales de la Historiografía Lingüistica. Actas del $V$ Congreso Internacional de la Sociedad Española de Historiografía Lingüistica. 
Murcia, 7-11 de noviembre de 2005, Murcia, Universidad de Murcia, 2006, pp. $995-$ 1007.

D. Maingueneau, Nouvelles tendances en analyse du discourse, Paris, Hachette, 1987.

E. Méndez García de Paredes, "Nominalización y tipo de texto", en J. L. Girón Alconchel et al. (eds.), Estudios ofrecidos al profesor José Jesús de Bustos Tovar, Madrid, Universidad Complutense de Madrid, 2003, vol. II, pp. 1015-1031.

S. Moirand, "Le rôle anaphorique de la nominalisation dans la presse écrite", Langue Française, 28, 1973, pp. 60-78.

A. Paz y Melia, "Noticia del autor y de su obra", en Avisos de don Jéronimo de Barrionuevo (1654-1658), ed. de A. Paz y Melia, Madrid, Atlas, 1968, pp. 3-12.

A. Pelo, "I 'nomi generali' nella lingua dei giornali italiani”, en K. Lichem, E. Mara y S. Knaller (eds.), Parallela 2. Aspetti della sintassi dell'italiano contemporaneo. Atti del $3^{\circ}$ incontro italo-austriaco di linguisti a Graz, 28-31 maggio 1984, Tübingen, Gunter Narr, 1986, pp. 205-214.

L. Pons Rodríguez, "La qual cibdad: las relativas con antecedente adjunto del siglo XIII a hoy. Evolución de un procedimiento cohesivo", Romanistisches Jabrbuch, e.p.

U. Vignuzzi, "I 'nomi generali' in italiano: alcuni problemi tra sintassi e semantica", en K. Lichem, E. Mara. y S. Knaller (eds.), Parallela 2. Aspetti della sintassi dell'italiano contemporaneo. Atti del $3^{\circ}$ incontro italo-austriaco di linguisti a Graz, 28-31 maggio 1984, Tübingen, Gunter Narr, 1986, pp. 317-328.

\author{
Margarita Borreguero Zuloaga \\ mbzuloag@filol.ucm.es \\ Álvaro S. Octavio de Toledo y Huerta \\ lafacera@hotmail.com \\ Dpto. de Filología Italiana \\ Facultad de Filología (Edif. A) \\ Universidad Complutense de Madrid \\ Ciudad Universitaria $\mathrm{s} / \mathrm{n}$ \\ E-28040 Madrid
}

Fecha de recepción: 10/01/2008

Fecha de aceptación: 26/06/2008 